\title{
Combining morphological and genomic evidence to resolve species diversity and study speciation processes of the Pallenopsis patagonica (Pycnogonida) species complex
}

Jana S. Dömel ${ }^{1 *}$, Till-Hendrik Macher ${ }^{1}$, Lars Dietz ${ }^{2}$, Sabrina Duncan ${ }^{3}$, Christoph Mayer $^{2}$, Andrey Rozenberg ${ }^{4}$, Katherine Wolcott ${ }^{3}$, Florian Leese ${ }^{1,5}$ and Roland R. Melzer ${ }^{3,6,7}$

\begin{abstract}
Background: Pallenopsis patagonica (Hoek, 1881) is a morphologically and genetically variable sea spider species whose taxonomic classification is challenging. Currently, it is considered as a species complex including several genetic lineages, many of which have not been formally described as species. Members of this species complex occur on the Patagonian and Antarctic continental shelves as well as around sub-Antarctic islands. These habitats have been strongly influenced by historical large-scale glaciations and previous studies suggested that communities were limited to very few refugia during glacial maxima. Therefore, allopatric speciation in these independent refugia is regarded as a common mechanism leading to high biodiversity of marine benthic taxa in the high-latitude Southern Hemisphere. However, other mechanisms such as ecological speciation have rarely been considered or tested. Therefore, we conducted an integrative morphological and genetic study on the P. patagonica species complex to i) resolve species diversity using a target hybrid enrichment approach to obtain multiple genomic markers, ii) find morphological characters and analyze morphometric measurements to distinguish species, and iii) investigate the speciation processes that led to multiple lineages within the species complex.

Results: Phylogenomic results support most of the previously reported lineages within the P. patagonica species complex and morphological data show that several lineages are distinct species with diagnostic characters. Two lineages are proposed as new species, P. aulaeturcarum sp. nov. Dömel \& Melzer, 2019 and P. obstaculumsuperavit sp. nov. Dömel, 2019, respectively. However, not all lineages could be distinguished morphologically and thus likely represent cryptic species that can only be identified with genetic tools. Further, morphometric data of 135 measurements showed a high amount of variability within and between species without clear support of adaptive divergence in sympatry.

(Continued on next page)
\end{abstract}

\footnotetext{
*Correspondence: jana.doemel@uni-due.de

${ }^{1}$ Aquatic Ecosystem Research, Faculty of Biology, University of

Duisburg-Essen, Universitaetsstr. 5, 45141 Essen, Germany

Full list of author information is available at the end of the article
}

(c) The Author(s). 2019 Open Access This article is distributed under the terms of the Creative Commons Attribution 4.0 International License (http://creativecommons.org/licenses/by/4.0/), which permits unrestricted use, distribution, and reproduction in any medium, provided you give appropriate credit to the original author(s) and the source, provide a link to the Creative Commons license, and indicate if changes were made. The Creative Commons Public Domain Dedication waiver (http://creativecommons.org/publicdomain/zero/1.0/) applies to the data made available in this article, unless otherwise stated. 


\begin{abstract}
(Continued from previous page)
Conclusions: We generated an unprecedented molecular data set for members of the $P$. patagonica sea spider species complex with a target hybrid enrichment approach, which we combined with extensive morphological and morphometric analyses to investigate the taxonomy, phylogeny and biogeography of this group. The extensive data set enabled us to delineate species boundaries, on the basis of which we formally described two new species. No consistent evidence for positive selection was found, rendering speciation in allopatric glacial refugia as the most likely model of speciation.
\end{abstract}

Keywords: Sea spider, Marine benthos, Antarctica, Patagonia, Integrative taxonomy, Target hybrid enrichment, Cryptic species, Selection

\section{Background}

The diversity of the marine benthos of the Southern Hemisphere has been influenced by large scale extension of grounded glaciers on the Patagonian and Antarctic continental shelves during repeated glacial cycles in the Plio- and Pleistocene [17, 29, 78]. Several studies suggested that benthic life was limited to few isolated refugia in which independent divergence and lineage sorting processes promoted today's high species diversity in Southern Ocean and Patagonian shelf habitats [1, 15, 30, 34, 51]. Molecular taxonomic studies added evidence on the role of glacial impacts on species divergence by reporting many previously unrecognized species (often referred to as "cryptic species") over the last few decades that often show non-overlapping, allopatric distribution ranges $[1,39,51,83]$.

One animal group with remarkable (cryptic) species diversity are sea spiders $[20,25,26,48,57,81]$. Sea spiders, or pycnogonids, are a group of exclusively marine arthropods that are especially diverse in the Southern Ocean [6].

One prominent example for high species diversity is the Pallenopsis patagonica (Hoek, 1881) [42] sea spider species complex. Pallenopsis patagonica has a holobenthic life cycle and is reported to occur with a circumpolar distribution around sub-Antarctic islands and on the continental shelf of Antarctica as well as southern South America [62], i.e. in regions that were strongly impacted by glaciations during the last ice ages [58]. Since its first description by Hoek [42], several authors have commented on the high morphological variability of $P$. patagonica and suggested that it represents a species complex [32, 40, 55, 81]. However, species delineation within this complex is difficult and there is a long history of attempts to resolve this question by either splitting the species when describing new species often based on a small number of specimens (e.g. [40, $41,61,68]$ ), or by lumping several species together declaring them synonymous (e.g. [13]). This culminated in two drastically different surveys by Pushkin [69] and Child [13]. While Pushkin [69] described more new species for the species complex, Child [13] refuted this and instead recognized only one, $P$. patagonica, to which he attributed a high variability. At the moment, four formerly described species are considered synonyms of P. patagonica: P. glabra (Möbius, 1902) [61], P. hiemalis (Hodgson, 1907) [40], P. meridionalis (Hodgson, 1915) [41] and P. moebiusi (Pushkin, 1975) [68, 7, 13]. Furthermore, there are more closely related species from the Southern Hemisphere whose relationship to or position within the species complex is unclear, e.g. P. buphtalmus (Pushkin, 1993) [69], P. latefrontalis (Pushkin, 1993) [69], P. macneilli (Clark, 1963) [14] and P. notiosa (Child, 1992) [12]. Hence, several studies have addressed this issue in recent years by adding genetic data. First, Weis et al. [81] reported that mostly sub-Antarctic specimens previously assigned to $P$. patagonica can be genetically divided into several groups based on mitochondrial cytochrome $c$ oxidase subunit I (COI) data. Weis et al. [81] also reported high morphological variability within the species complex. Based on the genetic and morphological differences, a new species was described, named P. yepayekae (Weis, 2014) [81]. Further groups within the species complex were suggested based on molecular data reported by Harder et al. [37] for Antarctic $P$. patagonica specimens. The authors defined ten distinct clades (labelled A-J) using the mitochondrial COI marker [37]. To validate the proposed number of clades and to exclude mito-nuclear discordances, which can be found in other pycnogonids, e.g. Colossendeis megalonyx (Hoek, 1881) [42, 20], Dömel et al. [26] investigated the highly variable nuclear internal transcribed spacer (ITS) marker for previously studied clades. In contrast to $C$. megalonyx, most lineages of the $P$. patagonica species complex were supported by both markers (only a few recently diverged ones were not). Thus, no evidence for mito-nuclear discordance was found. This suggested that the distinct lineages represented species defined based on the biological species concept. With additional specimens studied by Dömel et al. [26], additional clades were identified. Altogether, 19 clades with mostly regional distribution patterns were proposed as independently evolving 
lineages under the specific name patagonica (labelled ANT A-N and SUB 1-5 in [26], according to their geographic occurrence).

So far, no diagnostic morphological characters are known to delineate clades and characterise new species within the $P$. patagonica species complex, which, however, would be critically important in order to assess the benthic diversity of the Southern Hemisphere and test hypotheses regarding the underlying evolutionary processes.

Many studies on benthic invertebrates, especially on benthic brooders that lack pelagic larval stages like sea spiders, have interpreted the fact that species typically showed allopatric distribution patterns as evidence for lineage sorting in independent ice-free refugia $[1,38,39,51,74]$.

However, one study on the sea slug Doris kerguelenensis (Bergh, 1884) [8] that occurs in the Southern Ocean, as well as sub-Antarctic waters, suggested that interspecific competition for prey was involved in speciation [83]. Similarly, Rutschmann et al. [70] tested for adaptive speciation and radiation in notothenioid fish and found lineage-independent ecological differentiation into different niches probably as a result of positive selection. This provides evidence that consideration of genetic drift and independent lineage development in isolated refugia may not suffice to explain the enormous diversity in southern marine benthic habitats $[16,33]$. In fact, Antarctic and sub-Antarctic waters bear such a diverse range of extreme and different habitats and display diverse biotic interactions that speciation due to ecological divergence should more explicitly be explored as a potential process for speciation. In order to test for evidence of selection, quantitative evidence for functionally relevant changes in the genome has to be provided. With the availability of new analytical techniques for morphology (e.g. micro-computed tomography; $\mu \mathrm{CT}$ ) and genetics (Next Generation Sequencing (NGS), e.g. target hybrid enrichment; [27, 59]), it becomes possible to generate large integrative data sets. Target hybrid enrichment, i.e. a technique that captures specific genes with known homology across a taxonomic group using synthetic probes, offers an immense potential to test for genes under selection, especially in poorly studied organisms such as all Southern Hemisphere marine benthic invertebrate species. Hence, this method can also be used to further investigate the species diversity and to test competing hypotheses and compare neutral vs. non-neutral speciation hypotheses, i.e. lineage sorting in bottlenecked refugia vs. adaptive divergence. By combining genomic and morphometric data sets, greater morphological differences are expected especially for taxa living in sympatry in contrast to those living in allopatry due to potential niche specialisation in form of ecological character displacement [18, 19, 72].

Therefore, in this study we integrate all previous data on the $P$. patagonica species complex, combine them with genomic data obtained via target hybrid enrichment, analyses of morphological features using conventional observation methods and meristic data to study patterns of diversity and underlying evolutionary processes within the $P$. patagonica species complex. Specifically, we address the following questions:

Do genome-wide data add further information about previously unrecognised species diversity within the $P$. patagonica species complex?

Do we find morphological characters to distinguish the independently evolving lineages of the P. patagonica species complex and formally describe new species?

Do we find evidence for adaptive divergence at morphological or genetic level or do neutral evolutionary processes suffice to explain the observed species diversity?

\section{Results}

The sample set included specimens of Pallenopsis buphtalmus (corresponding to mitochondrial clade ANT_M in [26]), P. latefrontalis (ANT_F), P. notiosa (SUB_3) and P. yepayekae (Pye.1) as well as of further potential species within $P$. patagonica, i.e. ANT_C, ANT_D, ANT_K, ANT_L, SUB_1, SUB_2, SUB_4 and SUB_5. We refer to this set of putative species as the $P$. patagonica species complex (also P. patagonica sensu lato in [26]), since using the key in Child [12] would (erroneously) assign all those species to the morphospecies $P$. patagonica.

\section{Genomic analyses}

The obtained dataset consisted of 61 individuals of the Pallenopsis patagonica species complex. One individual of P. pilosa (Hoek, 1881) [42] genotyped by us and a previously published transcriptome assembly of Anoplodactylus insignis (Hoek, 1881) [42] [28] were added as outgroups in genetic analyses. When analyzing all Pallenopsis specimens on the nucleotide level, 821 out of 1607 targeted EOGs (Eukaryotic Orthologous Groups), which in our case are putative single-copy groups of orthologous genes, were recovered with a total alignment length of $474,954 \mathrm{bp}$. The data set used to infer a reliable root by including $A$. insignis was analysed on the amino acid level to reduce the branch length to the outgroup. This alignment included only EOGs for which a sequence of $A$. insignis was present and sites with a sequence coverage of at least $50 \%$, which reduced the data set to 208 EOGs and 22,018 aa (corresponding to $66,054 \mathrm{bp}$ ). Furthermore, sequences that were outliers on the amino acid level were excluded. The models of 
evolution chosen by ModelFinder for the nucleotide data set were GTR + R2 for the first, TIM + R2 for the second and GTR + R4 for the third codon positions. For the amino acid alignment including $A$. insignis, JTT $+\mathrm{F}+\mathrm{R} 3$ was chosen as the best fitting model.

Single-nucleotide polymorphism (SNP) calling for all Pallenopsis samples (i.e. including P. pilosa) resulted in 2527 SNPs from 168 EOGs. This data set was only used for construction of a phylogenetic tree.

Phylogenetic analyses of the amino acid data set revealed that the $P$. patagonica species complex represents a monophyletic group with $P$. pilosa and $A$. insignis representing a joint outgroup (Additional file 1). In particular $P$. pilosa was shown to be a sister group to the $P$. patagonica species complex, as assumed in previous studies [26, 81]. Further analyses were conducted with the nucleotide data set not including A. insignis. Separate phylogenetic analyses based on the EOG alignment (in the following referred to as the EOG data set) and the variant calling (in the following referred to as the SNP data set) including all Pallenopsis specimens resulted in phylograms with identical topologies (Fig. 1 and Additional file 2) but the EOG-based analysis had higher bootstrap support (bs) values and is discussed herein. Two major groups are discernible within the $P$. patagonica species complex, one including specimens assigned to all of the Antarctic clades (ANT) except ANT_N (from now on referred to as the "Antarctic supergroup") and one including specimens from all Patagonian clades (SUB) plus ANT_N (from now on referred to as "Patagonian supergroup"). The "Antarctic supergroup" is comprised of two major lineages, ANT_C/D/M and ANT_F/K/L. More detailed divisions of those groups are in agreement with the clades delineated in Dömel et al. [26]. There is also a strong support for the geographical divide in ANT_D and P. latefrontalis (ANT_F) into specimens from the Antarctic shelf (both 100\% bs) and sub-Antarctic islands (South Georgia with 99\% bs, and Bouvet Island with $96 \%$ bs, respectively). Within the "Patagonian supergroup", SUB_4 and SUB_5 together represent the basalmost group of the "Patagonian supergroup" with SUB_4 being paraphyletic with respect to SUB_5. Analogously, SUB_1 and SUB_2 appear not strictly monophyletic with respect to each other, since specimens from Burdwood Bank belonging to both clades group together. ANT_N is nested within the "Patagonian supergroup", as are P. notiosa (SUB_3) and P. yepayekae.

For the principal component analyses (PCA) three SNP data sets were analysed. The first data set contained all specimens of the P. patagonica species complex and included 2543 SNPs from 175 EOGs. Furthermore, separate data sets for the "Patagonian supergroup" and the "Antarctic supergroup" yielded 2047 SNPs from 183 EOGs and 2487 SNPs from 216 EOGs, respectively. For the first SNP data set ( $P$. patagonica species complex), 16 significant axes were found. There is a clear differentiation between five groups (Fig. 2a). All Antarctic clades cluster together, with the exception of ANT_N. The Patagonian clades are divided into four groups, SUB_1/ 2, P. notiosa (SUB_3), SUB_4/5 and P. yepayekae (Pye.1). Analyses of the data set divided into the two supergroups obtained no significant axes for the "Patagonian supergroup". For the "Antarctic supergroup", the first seven axes were significant and showed a differentiation into the clades previously proposed by Dömel et al. [26] (Fig. 2b).

For the clustering analyses, the cross entropy with the lowest median was chosen (Additional file 3). By this criterion, the best number of ancestral populations was seven $(K=7)$. The plot of the sparse nonnegative matrix factorization (sNMF) mostly supported the groupings obtained with the PCA. The differences were that ANT_K and ANT_L as well as SUB_1 and SUB_2 grouped together and showed similar proportions of the same ancestral populations (Fig. 3).

For selection tests, a sequence alignment including only positions that were present in at least $50 \%$ of the samples was used. This resulted in an alignment of 82,782 bp recovering 293 EOGs. Seventeen codons within 17 EOGs and 49 codons within 38 EOGs under selection using the Fast Unconstrained Bayesian AppRoximation (FUBAR) and the Mixed Effects Model of Evolution (MEME), respectively, were detected. Sixteen codons within 16 EOGs were shared between both methods. Furthermore, no branches under selection were detected, irrespective of the applied test (aBSREL or BUSTED; see Methods).

\section{Morphology Morphometrics}

Morphometric measurements were taken for 37 individuals (a table including all measurements is provided in Additional file 4) but due to damage during trawling, transport, storage or preceding genetic analysis, distal articles of appendices and hence data for those were often missing. After averaging measurements for bilateral characters, the amount of missing data was reduced by about three quarters. For further analyses, filtered data sets including 38 and 39 characters for the absolute and relative values, respectively, were used. PCA plots using all specimens did not show separation into clades but a trend for a division of sub-Antarctic and Antarctic samples (Additional file 5).

To avoid the problem of overfitting, character sets optimal for species separation in discriminant analysis (LDA) were searched for using a heuristic approach. 


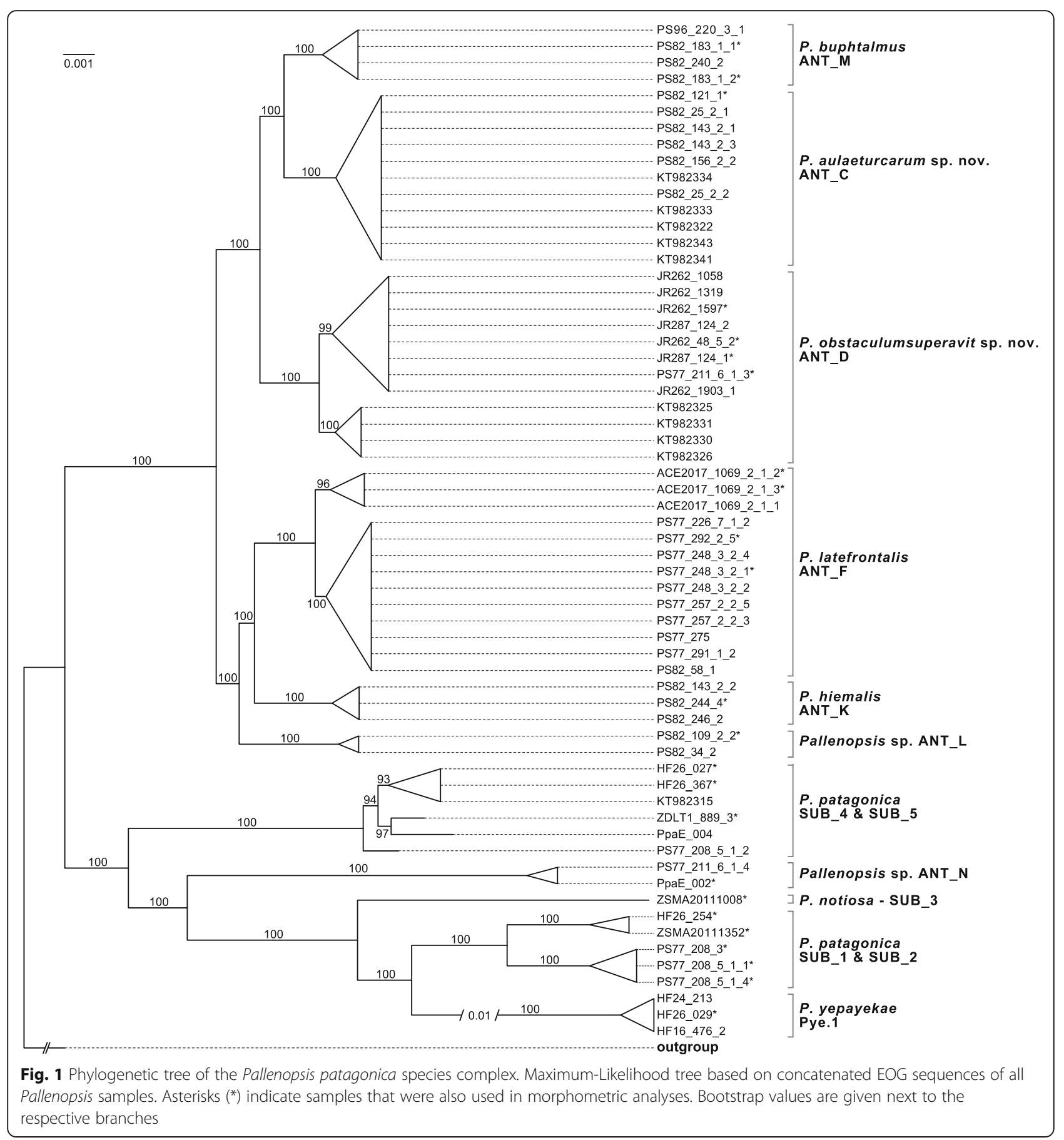

Therefore, only clades with a minimum of three individuals were included resulting in a data set of seven clades and 29 specimens. Absolute as well as relative values expressed as proportion of the trunk length were used.

For both data sets (absolute and relative values) multiple iterations of character selection were performed and it was recorded how often a character was added to an LDA model in individual optimizations and what its contribution was (see Table 1). The LDA plots of both data sets based on the character combinations with best performance clearly separated all clades from each other, except for clade ANT_D and ANT_F when looking at the absolute values (Fig. 4). Furthermore, analysis of cross-validation confusion matrices confirmed that these results were not dominated by overfitting artefacts, with the correctness rate being higher for the relative values 


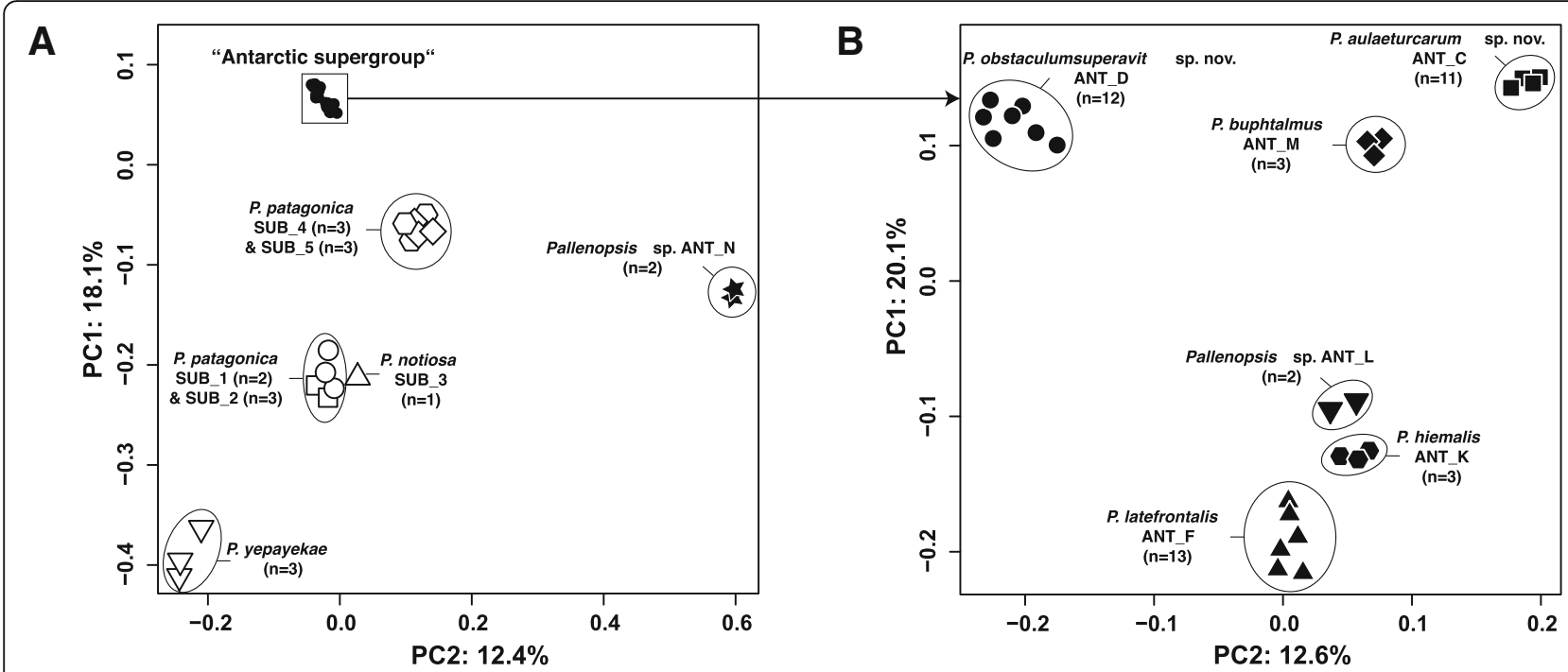

Fig. 2 PCA from genomic data of the Pallenopsis patagonica species complex. PCA plots based on genomic data of a) all samples of the Pallenopsis patagonica species complex and b) samples of the "Antarctic supergroup"

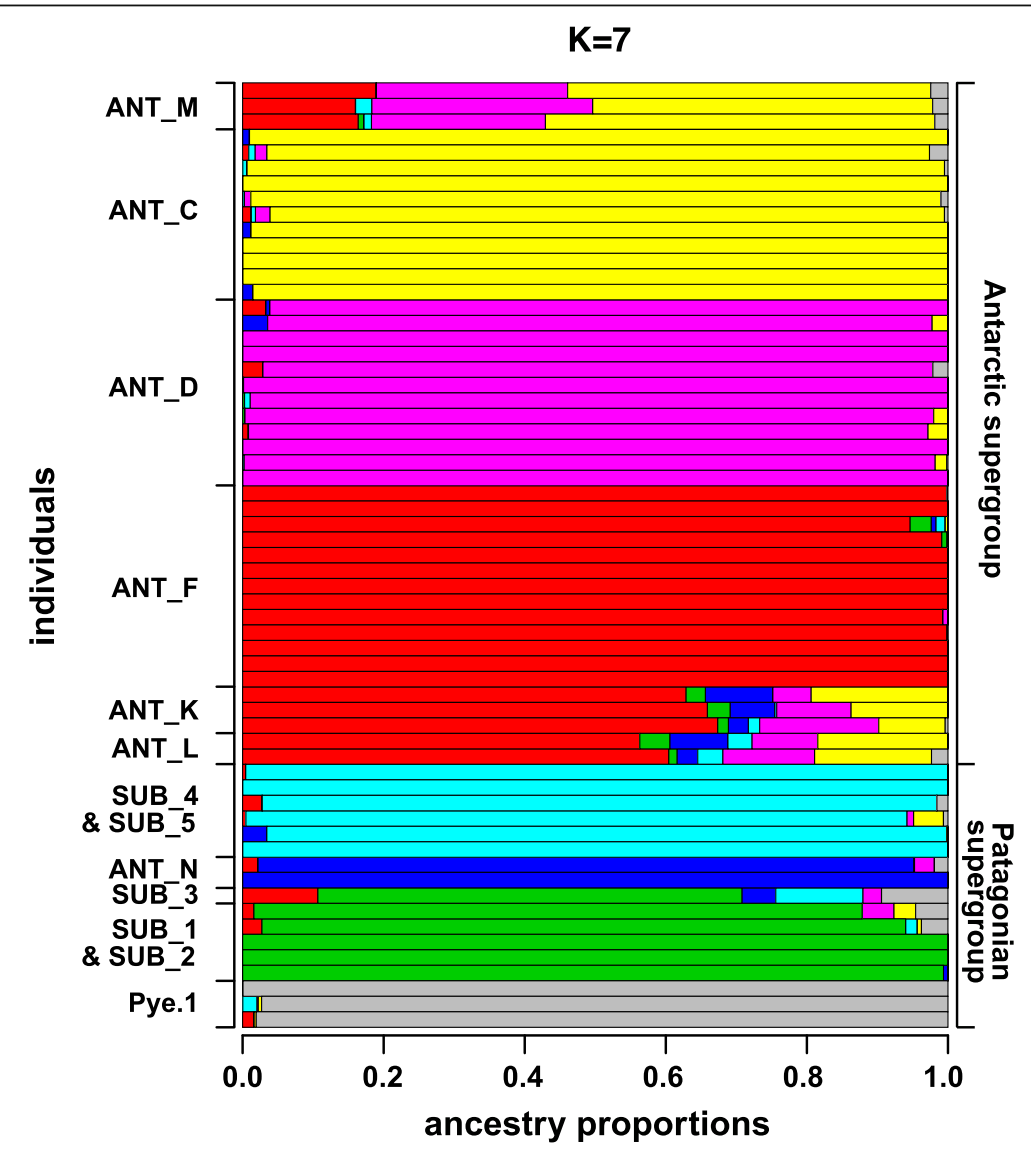

Fig. 3 sNMF analyses of the Pallenopsis patagonica species complex. Graphical illustration of ancestry proportion estimates for all samples with $K=7$. Estimated proportions of ancestry populations are illustrated by different colors. Each horizontal bar represents one specimen 


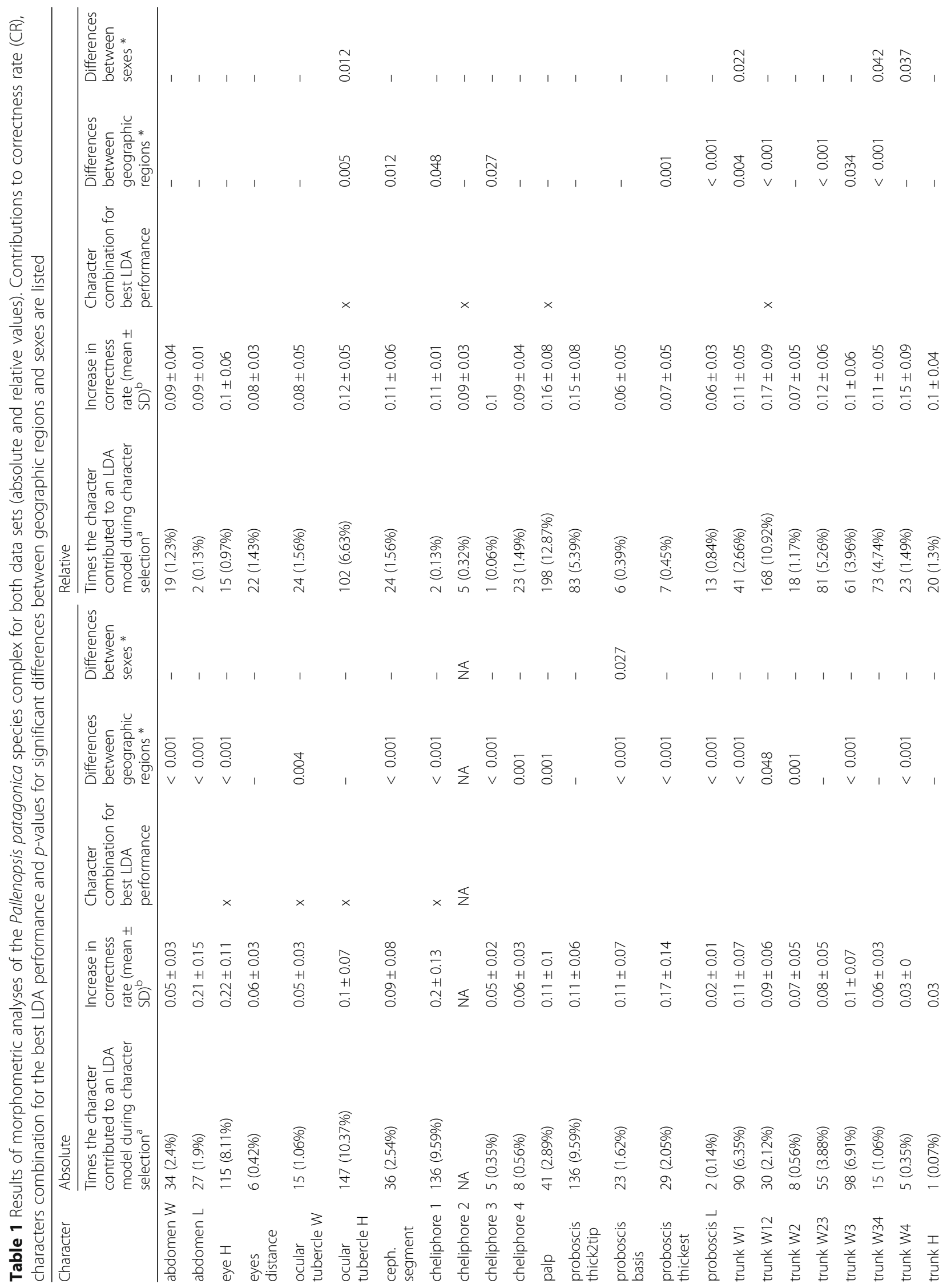


Dömel et al. Frontiers in Zoology

(2019) 16:36

Page 8 of 29

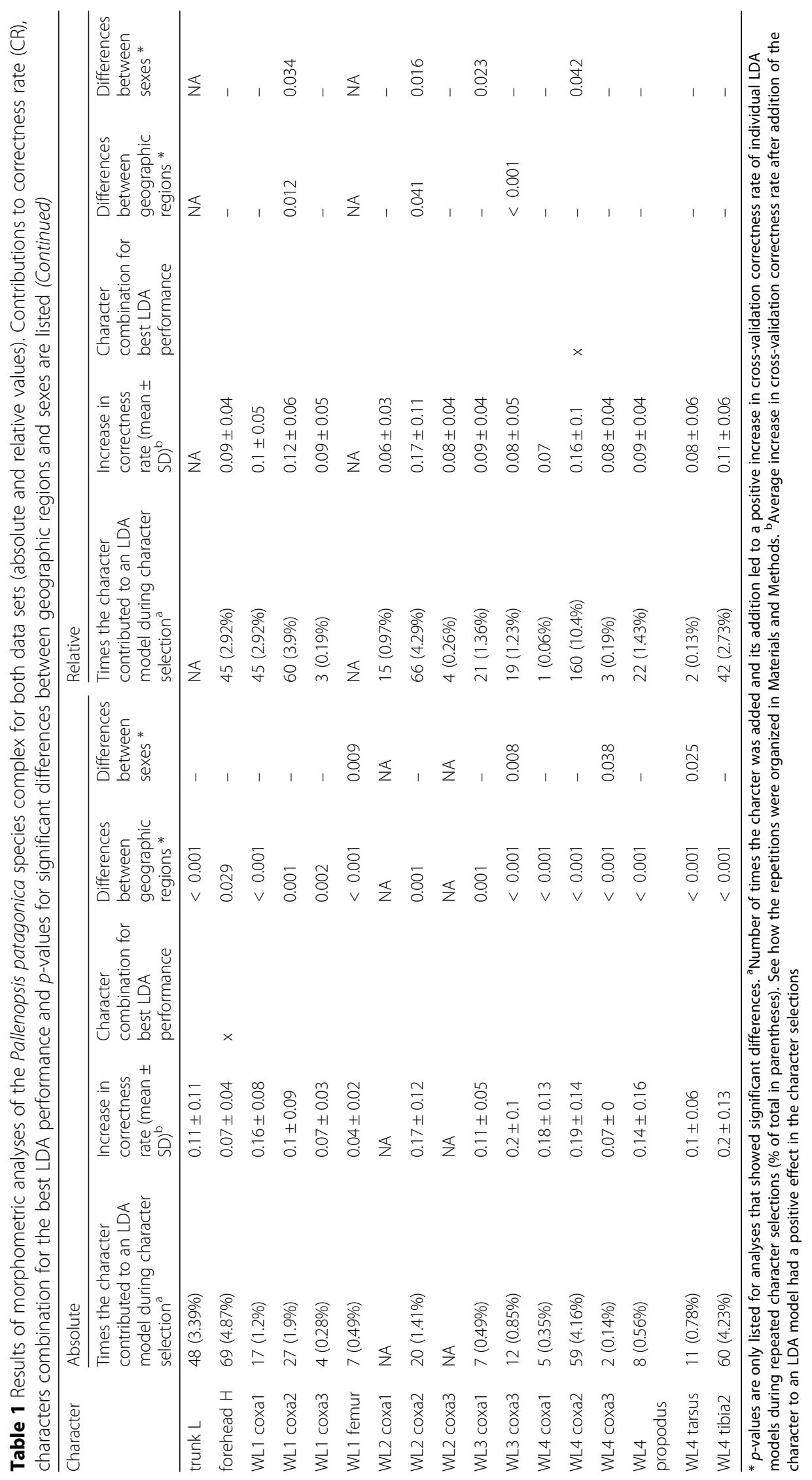



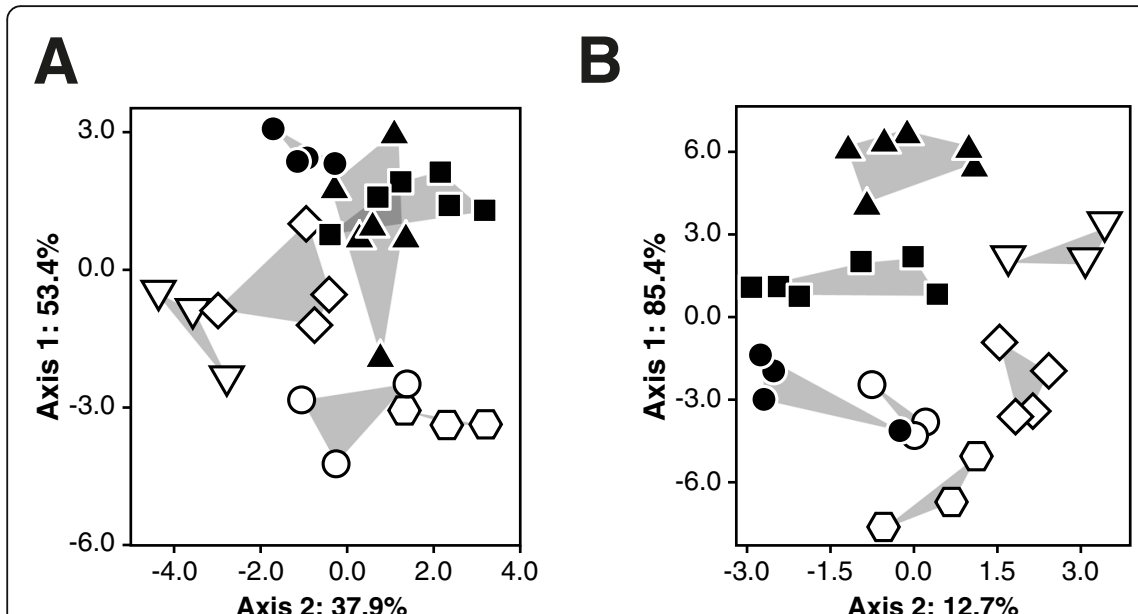

- P. aulaeturcarum sp. nov.

- ANT_C

- P. obstaculumsuperavit sp. nov. - ANT_D

A P. latefrontalis - ANT_F

O $P$. patagonica - SUB_2

$\checkmark P$. patagonica - SUB_4

$\checkmark P$. patagonica - SUB_5

$\nabla P$. yepayekae - Pye. 1

Fig. 4 LDA of the Pallenopsis patagonica species complex. Ordination of the filtered morphometric data set using different combination of characters for a) absolute values (ocular tubercle $\mathrm{H}$, ocular tubercle W, eye $\mathrm{H}$, forehead $\mathrm{H}$, cheliphore 1), and b) relative values (trunk W12, ocular tubercle H, palp, cheliphore 2, WL4 coxa2)

(0.83) than for the absolute values (0.76) (Table 2). Here, ANT_F and SUB_5 had many misassignments (absolute data set). Analogously, PCAs for both data sets showed that the clades ANT_D and ANT_F could not be separated from each other for the data set including absolute values (see matrices of all PCs in the Additional file 6).

Significant differences of characters between clades were found for neither of the two data sets after Bonferroni correction. However, 33 and 14 significant differences between specimens from the different geographic regions (SUB and ANT) for absolute and relative value, respectively, were found (Table 1). In all cases, the characters of the Antarctic samples were larger than of the Patagonian ones. As for analyzed specimens, males were more frequent in sub-Antarctic (75\%) and females preponderated in Antarctic clades (65\%), characters were also tested for significant differences between sexes. There were five and eight significant differences for absolute and relative values, respectively, of which five characters for each data set also showed significant differences between geographic regions (see Table 1).

\section{Morphological characters}

Using the morphological key for Pallenopsis [82] from [13], all specimens analysed were assigned to $P$. patagonica. However, we observed consistent morphological features for several groups. Specimens that occur south of the Antarctic Polar Front are larger in body size and have longer legs in comparison to those from the Patagonian clades. Also, the distance between the lateral processes is longer for the Antarctic specimens. Furthermore, the rudimentary palp is larger for Antarctic individuals (Fig. 5).

Specimens from Patagonian clades showed great variation and almost no suitable morphological characters for clade assignments. Only P. notiosa (SUB_3)

Table 2 Cross-validation confusion matrices for morphometric data set of the Pallenopsis patagonica species complex using absolute and relative values

\begin{tabular}{|c|c|c|c|c|c|c|c|c|c|c|c|c|c|c|}
\hline & \multicolumn{7}{|c|}{ absolute (correctness rate: 0.76 ) } & \multicolumn{7}{|c|}{ relative (correctness rate: 0.83 ) } \\
\hline & ANT_C & ANT_D & ANT_F & Pye.1 & SUB_2 & SUB_4 & $\overline{S U B \_5}$ & ANT_C & ANT_D & ANT_F & Pye.1 & SUB_2 & SUB_4 & SUB_5 \\
\hline ANT_C & 4 & 0 & 0 & 0 & 0 & 0 & 0 & 3 & 0 & 0 & 0 & 1 & 0 & 0 \\
\hline ANT_D & 1 & 5 & 0 & 0 & 0 & 0 & 0 & 1 & 5 & 0 & 0 & 0 & 0 & 0 \\
\hline ANT_F & 1 & 0 & 3 & 0 & 1 & 0 & 1 & 0 & 0 & 6 & 0 & 0 & 0 & 0 \\
\hline Pye.1 & 0 & 0 & 0 & 3 & 0 & 0 & 0 & 0 & 0 & 0 & 3 & 0 & 0 & 0 \\
\hline SUB_2 & 0 & 0 & 0 & 0 & 3 & 0 & 0 & 1 & 0 & 0 & 0 & 2 & 0 & 0 \\
\hline SUB_4 & 0 & 0 & 0 & 0 & 0 & 3 & 0 & 0 & 0 & 0 & 0 & 0 & 2 & 1 \\
\hline SUB_5 & 1 & 0 & 1 & 1 & 0 & 0 & 1 & 0 & 0 & 0 & 1 & 0 & 0 & 3 \\
\hline
\end{tabular}




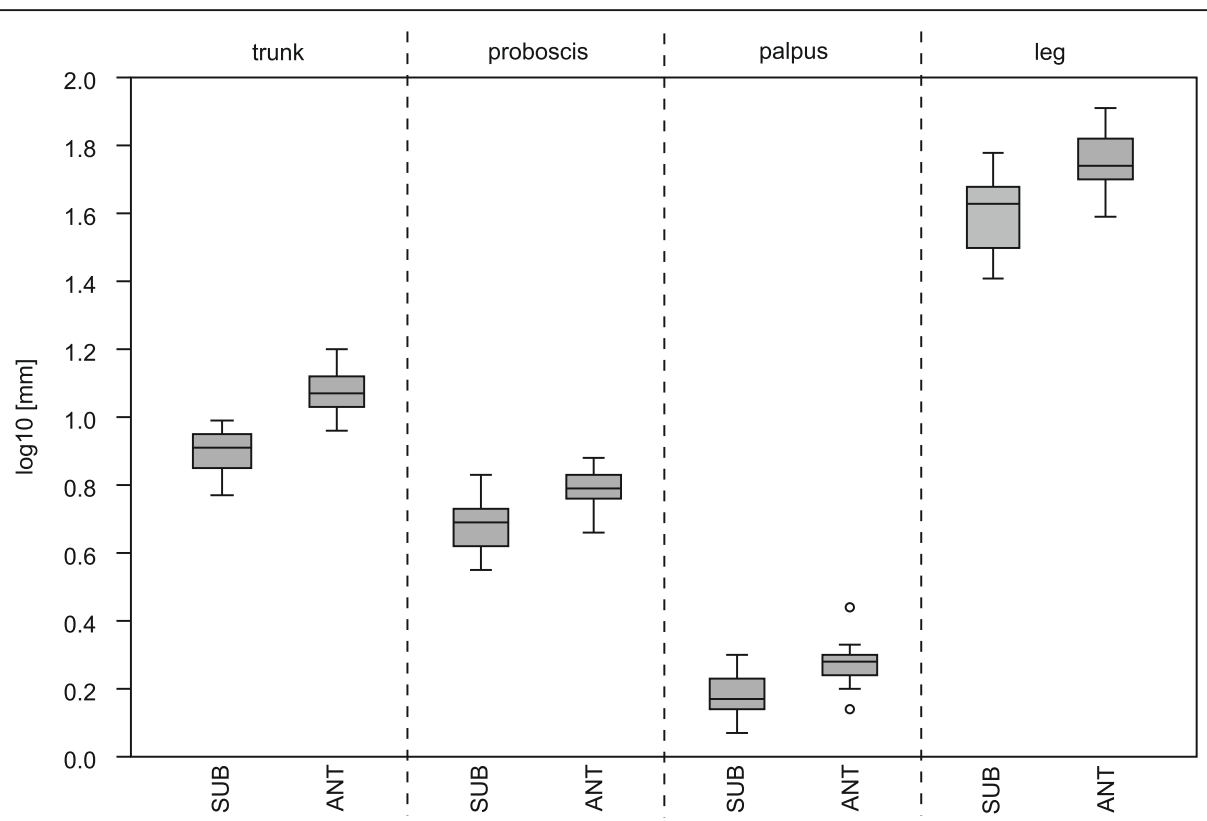

Fig. 5 Boxplot showing size differences in morphological structures of the Pallenopsis patagonica species complex. All comparisons show that characters of samples from ANT (Antarctica) are significantly larger than from SUB (Patagonian) (log 10 of absolute values used; $p=0.0000005, p=$ $0.00008, p=0.00042$ and $p=0.00012$, respectively)

can be distinguished from the others due to its rounded (rather than a pointed or slightly pointed) ocular tubercle and a very long second coxa, which exceeds the combined lengths of the first and third coxae (Fig. 6c,e).

Specimens from Antarctica can morphologically be divided into two groups which can be distinguished by the setae patches on the dorso-posterior margin of the trunk segments (Fig. 6d), that vary in size for specimens of ANT_C/D/M but are absent in those of ANT_F/K/L and ANT_N. Two Antarctic clades were identified as already described species, namely $P$. buphtalmus (ANT_M) and P. latefrontalis (ANT_L). Pallenopsis buphtalmus (ANT_M) can be distinguished from the other Antarctic species due to relatively short accessory claws. For $P$. latefrontalis (ANT_L) the second coxa is characteristically shorter than the combined lengths of the first and third coxae. A straight rather than a curved propodus is distinctive of ANT_K (Fig. 6b). Also, the lateral processes in this clade display a dorso-distally located crowning that differs from the frequently occurring but much smaller thickenings (Fig. 6a). Those characters were also described for P. hiemalis by Hodgson [40] and Pushkin $[68,69]$ by their slim segmented body, cylindrical proboscis, rudimentary palps, ten-articled ovigera in males, and slender legs with one main and two auxiliary claws [82].

\section{Pallenopsis aulaeturcarum sp. nov. Dömel \& Melzer urn:Isid:zoobank.org:act:72E41F8B-0A6F-4A5B-815A- 1C2CAB65AFA5}

Figures 7 a-g, 9 a-e

Type material

Holotype: PS82_156_2_1 (ZSM-A20160629), female, Weddell Sea, -75.507 (S), -27.486 (W), January 2014, depth: $281.5 \mathrm{~m}$.

Paratypes: PS82_121_1 (ZSM-A20160626), female, Weddell Sea, - 76.966 (S), - 32.945 (W), January 2014, depth: $265.2 \mathrm{~m}$. First leg pair and ovigera loose in the jar, proboscis of this individual was used for further analyses with the scanning electron microscope (SEM); PS82_156_2_2 (ZSM-A20160630), female, Weddell Sea, - 75.507 (S), 27.486 (W), January 2014, depth: $281.5 \mathrm{~m}$; PS82_223_1 (ZSM-A20160730), male, Weddell Sea, - 75.522 (S), 28.973 (W), February 2014, depth: $462 \mathrm{~m}$, both ovigera damaged, cement gland tube used for sex determination; PS82_174_3 (ZSM-A20160637), male, Weddell Sea, 74.491 (S), -30.977 (W), February 2014, depth: $529.7 \mathrm{~m}$, left oviger detached, no morphometric measurements available for this individual.

The type series is deposited in the Bavarian State Collection of Zoology, in the department Arthropoda varia.

Distribution Weddell Sea, from eastern tip of the Antarctic Peninsula $(-63.686,-56.859)$ to eastern Weddell 

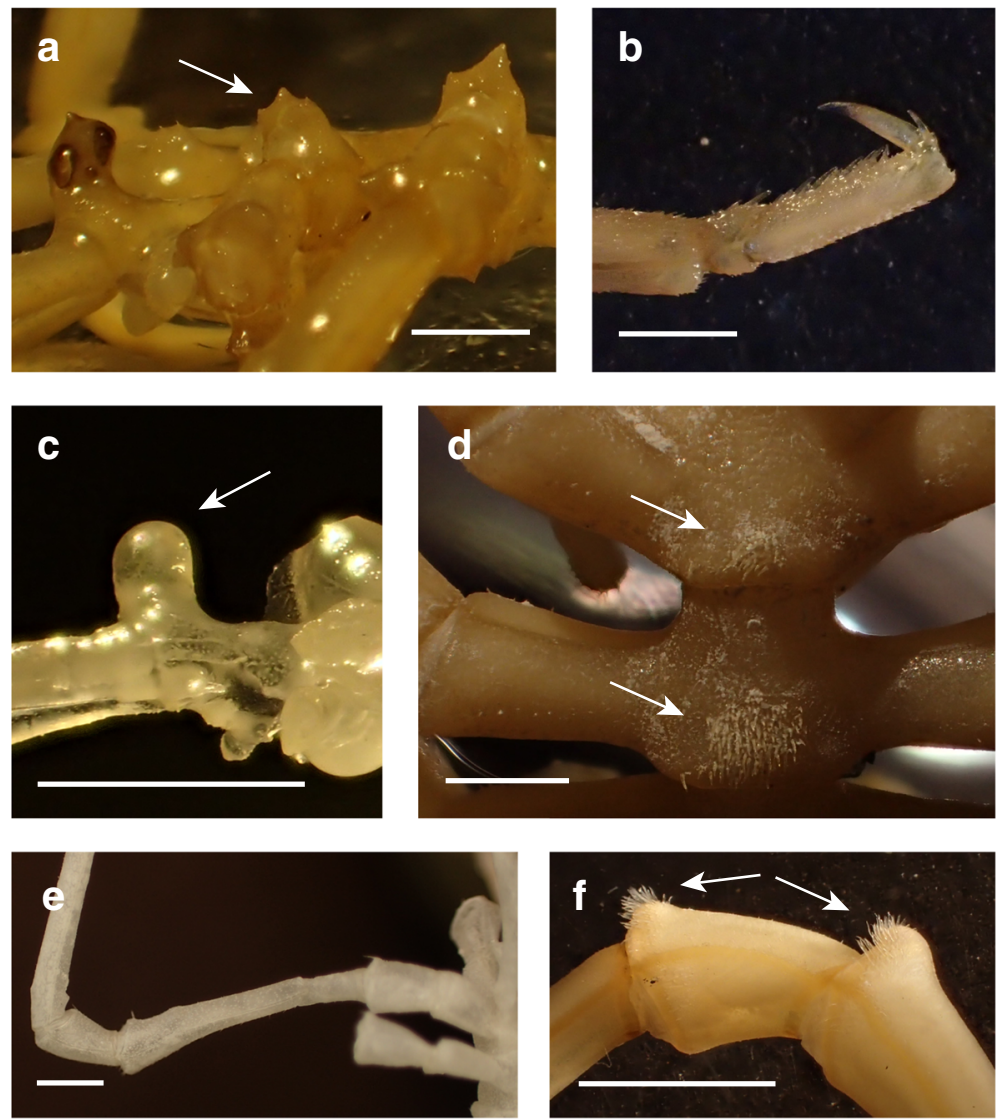

Fig. 6 Prominent morphological characters of various lineages of the Pallenopsis patagonica complex. a, dorso-distally located crowning (see arrow) of lateral processes in PS82_143_2_2 (P. hiemalis; ANT_K). b, straight propodus of PS82_143_2_2 (P. hiemalis; ANT_K). c, rounded ocular tubercle of ZSM-A20111008 (P. notiosa; SUB_3). d, setae patches (see arrows) on dorsal-posterior margin of three trunk segments of JR262_1058 (P. aulaeturcarum; ANT_D). e, coxae of ZSM-A20111008 (P. notiosa; SUB_3). f, detailed view of second and third coxa with bifurcated setae on distal margins (see arrows) of PS77_211_6_1_4 (Pallenopsis sp. ANT_N). Scale bars $=1.5 \mathrm{~mm}$

Sea $(-70.940,-10.489)$, and Bouvet Island (-54.425, 3.524).

Diagnosis Setae on posterior margin of trunk segments. More rows on ventral side (about three) than on dorsal side (one row). Abdomen oriented upwards.

Description (female) Size moderate, leg span less than $65 \mathrm{~mm}$. Trunk with distinct segment borders, ridges strongly expressed (Fig. 7a,b). Ridges on dorsal side smooth with few setae. Ventral surface covered with 2-3 rows of small clearly apparent spinules. Lateral processes separated by about the size of their diameter, U-shaped (Figs. 7a, 9a). Distal margins of all processes display fringe of small spinules. On dorsal side, these spinules are located on slight thickenings (Fig. 7b). Ocular tubercle situated on anterior end of cephalic segment. Top of ocular tubercle slightly bent backwards and pointed. Eyes prominent and pigmented, anterior eyes larger than posterior eyes. Proboscis sub-cylindrical, equally thick throughout and slightly directed downwards (Fig. 9a,b). It is about half the length of the trunk. Abdomen long, extending from the trunk oriented upwards and covered with few spinules (Figs. 7b, 9a). Cheliphores with two-articled scape, first article longer than second article (Fig. 7b). Ultimate cheliphore article (movable finger) equipped with setose pad. Moveable digit slightly longer than fixed digit, its tip curved. Inner margins straight and joined when closed. Setae pad has a triangular shape of which the whole length is attached to chela. Singlearticled, laterally placed palp represents the rudimentary state typical for the genus (Fig. 7b). It takes the form of an elongated bulb that is twice as long as wide. Female oviger composed of ten articles (Fig. 7e). Proximal articles broaden slightly towards the distal part of each article. Second article equal in length to the third article. Fourth oviger article more swollen and the longest of all. From fourth article onwards, article length decreases. 


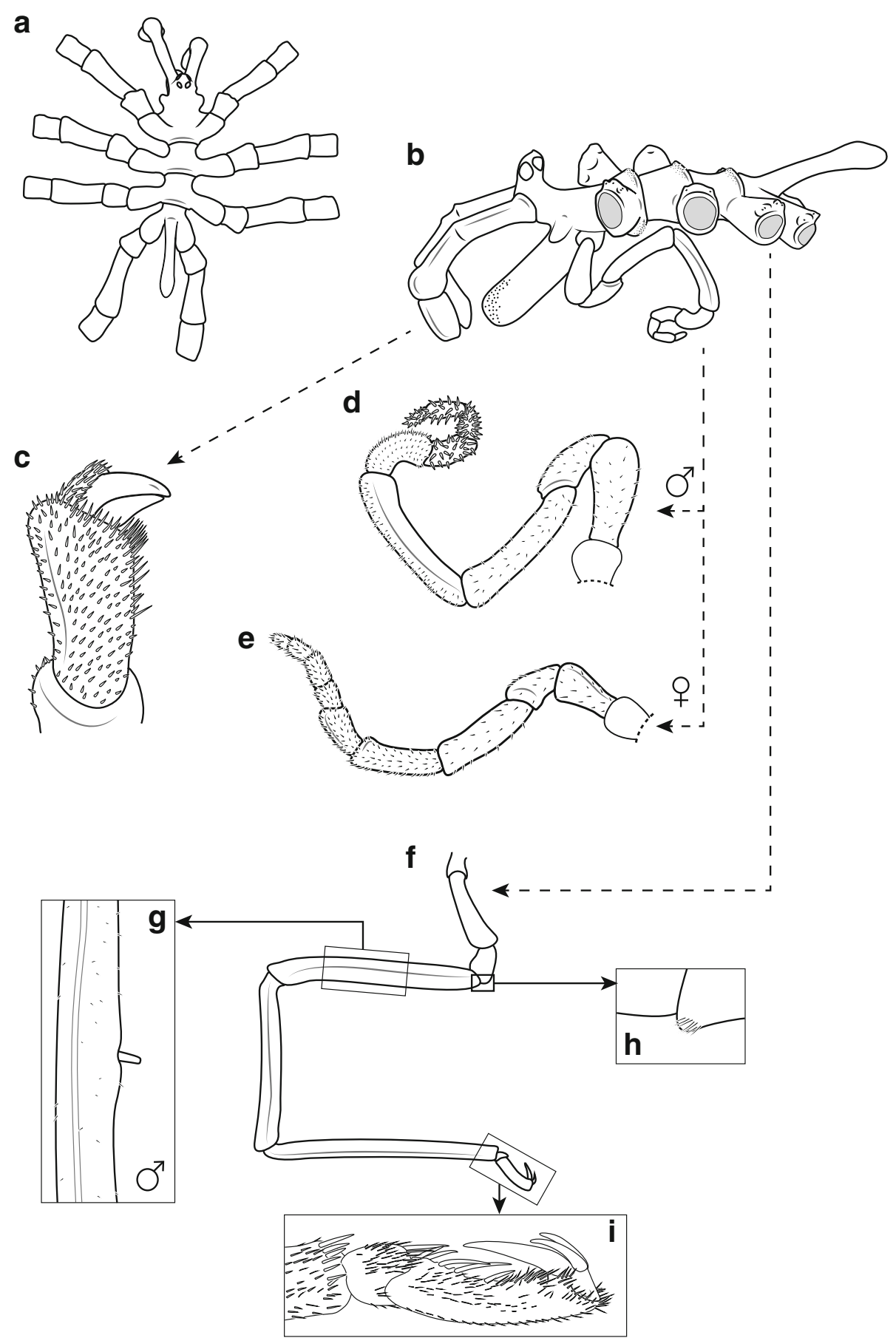

Fig. 7 Pallenopsis aulaeturcarum sp. nov. Dömel \& Melzer (clade ANT_C). (a), dorsal view. (b), lateral view of male. (c), cheliphore. (d), male oviger. $(\mathbf{e})$, female oviger. (f), walking leg with enlargement of cement gland tube $(\mathbf{g})$, setae on third coxa $(\mathbf{h})$, and propodus with claw and auxiliary claws (i)

Oviger articles are setose, with all setae pointing distally. Legs with several short setae (Fig. 7f,g). First and third coxa sub-equal. Second coxa about twice the length of third coxa (Fig. 7a,f). Assemblage of short setae on ventral side of second and third coxa (Fig. 7h, 9d). Setae without bifurcation. Femur and first tibia about equal in size. Second tibia slightly longer than other leg articles. Tarsus is short and armed with one big spine on the ventral side near its distal part and a couple of smaller lateral spines. Propodus slightly curved, with three to 
four heel spines that differ insignificantly in length, but the distal spine is the largest (Fig. 7i, Fig. 9e). The remaining sole is covered with many shorter spines. Claw dorsally curved, its inner margin straight, its tip curved. Two auxiliary claws about half the length of main claw. Sexual pores on all second coxae on ventrodistal surface. In contrast to the male, the female lacks cement gland tubes (see below).

Measurements (holotype in mm) Length of trunk (anterior margin of first trunk segment to distal margin of fourth lateral processes), 9.80; trunk width (across first lateral processes), 3.98; proboscis length, 4.27; abdomen length, 3.91; third right leg, coxa 1, 1.45; coxa 2, 4.68; coxa 3, 2.78; femur, 13.74; tibia 1, 11.66; tibia 2, 15.08; tarsus, 0.32; propodus, 2.46; claw, 1.72; auxiliary claws, 0.63 .

Different segments were measured in natural posture.

Male The general habitus and size of the male are similar to those of the female. Differences are in the sexual characters: oviger ten-articled (as is typical for the genus), but longer than in the female (Fig. 7d). Second articles, nearly twice the length of third article. Fourth and fifth articles the longest and equal in size. Distal articles more setose than proximal articles, with setae pointing in various directions. Long cylindrical cement gland tube is located in the center of the ventral side of the femur in a small recess on top of a little swelling (Figs. 7g, 9c). It is about a third of the diameter of the femur and points away from the podomere's surface in a nearly right angle. Sexual pores on ventral side of second coxae of third and fourth pair of legs.

Etymology The specific name aulaeturcarum stands for "the yard (aula) of the Turks (turcae)" and is dedicated to the eponymous pub in Munich called "Türkenhof" that was frequently visited to discuss the complex and very variable morphology of Pallenopsis. The good atmosphere and drinks definitely improved the spirit and inspired the authors.

Remarks This species belongs to the Pallenopsis patagonica s.l. species complex as defined in [26] and also analysed in [37]. In the previous studies, this species was defined as clade ANT_C or C, respectively.

There are no unique characters present for this new species which can be used to separate it from most other species of the genus, but the combination of its several diagnostic characters (shape of cheliphore pad, distances of lateral processes, presence of setae on ventral and dorsal side of trunk, as well as absence of long setae on legs and thickenings on lateral processes) makes it possible to distinguish it from the others.

\section{Pallenopsis obstaculumsuperavit sp. nov. Dömel urn:Isid:zoobank.org:act:69F7ADB8-26BB-4183-A178- 67EEBABAE8BE}

Figures $8 \mathrm{a}-\mathrm{g}, 9 \mathrm{f}-\mathrm{j}$

Type material

Holotype: JR262_1058 (ZSM-A20160708), female, South Georgia, -55.144, - 36.245, $195.21 \mathrm{~m}$, November/December 2011, missing legs: 3rd and 4th right side, 4th left side; one loose leg in the jar.

Paratypes: JR262_48_5_2 (ZSM-A20160713), female, South Georgia, - 54.284, - 36.083, 124.08 m, November/ December 2011; JR287_124_1 (ZSM-A20160691), male; South Georgia, -53.764, - 36.681, $151 \mathrm{~m}$, May 2013; JR287_152 (ZSM-A20160694), female, South Georgia, 53.758, - 36.690, $145 \mathrm{~m}$, May 2013, Proboscis of this individual was used for further analyses with the SEM; JR262_1597_2 (ZSM-A20160710), male, South Georgia, - 54.396, - 37.384, 174.98 m, November/December 2011; PS77_211_6_1_3 (ZSM-A20160696), female, Shag Rocks, - 53.402, - 42.668, 290.2 m, February 2011.

The type series is deposited in the Bavarian State Collection of Zoology, in the department Arthropoda varia.

Distribution Southern Ocean, from sub-Antarctic islands (South Georgia and Shag Rocks; -53.597, 41.214) as well as the Antarctic continental shelf (west and east of the tip of the Antarctic Peninsula; - 63.389, $-60.120)$.

Diagnosis Setae patches of half the width of lateral processes on first trunk segment and with size of width of whole lateral process for second and third trunk segment. Abdomen pointing downwards.

Description (female) Size moderate, leg span less than $85 \mathrm{~mm}$. Trunk with distinct segment borders, ridges strongly expressed (Fig. 8a,b). Ridges on dorsal side setae-rich with a setae patch of half the width of lateral processes on first segment and with size of width of whole lateral process for second and third trunk segment. Ventral surface covered with few setae. Lateral processes separated by about the size of their diameter, U-shaped (Figs. 8a, 9f). Distal margins of all processes display fringe of small spinules. On dorsal side, these spinules are located on slight thickenings (Fig. 8b). Ocular tubercle situated on anterior end of cephalic segment. Top of ocular tubercle slightly bent backwards and pointed. Eyes prominent and pigmented, anterior eyes larger than posterior eyes. Proboscis sub-cylindrical, equally thick throughout and slightly directed downwards (Fig. 9f,g). It is about half the size of the trunk. 


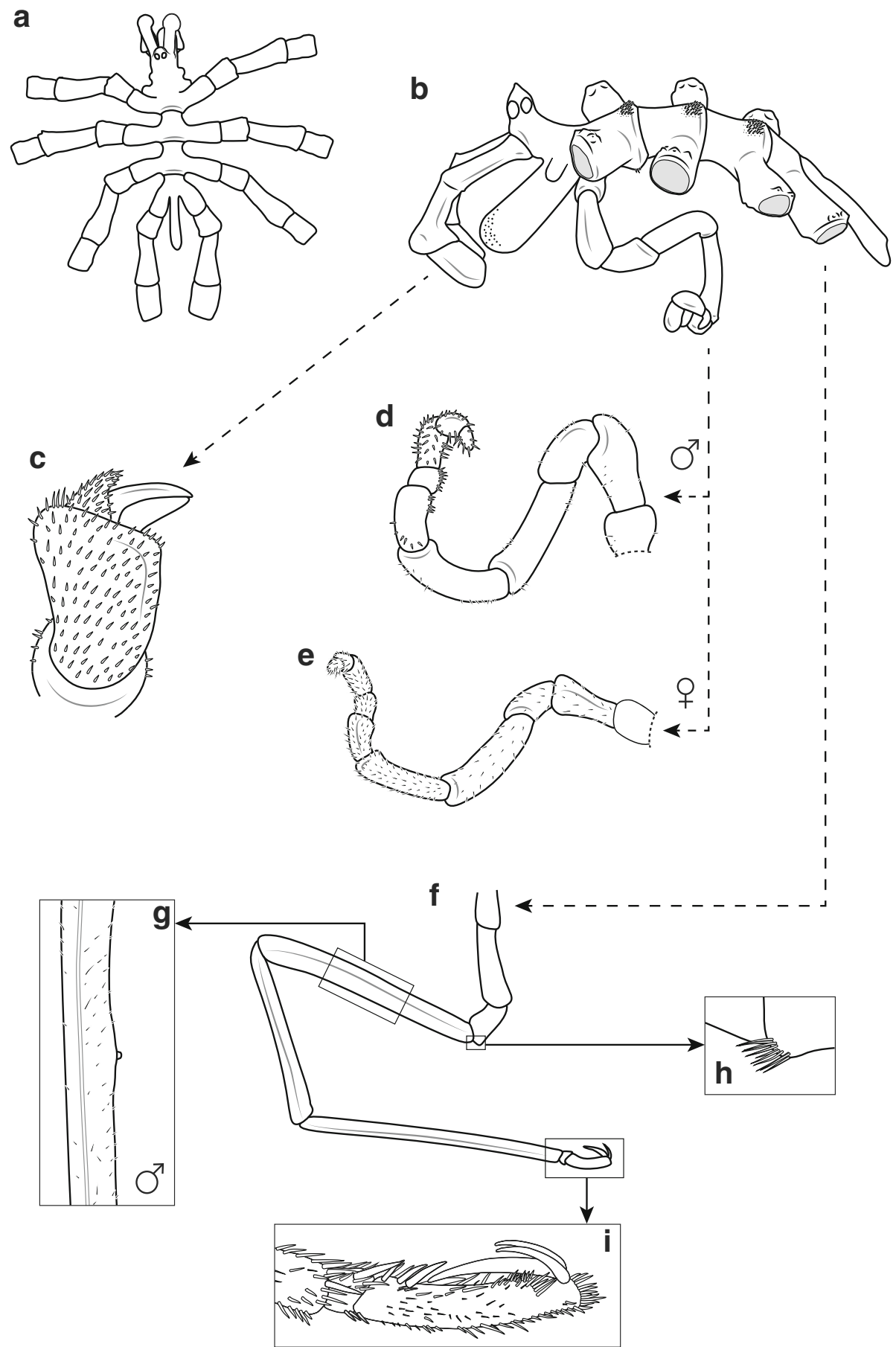

Fig. 8 Pallenopsis obstaculumsuperavit sp. nov. Dömel (clade ANT_D). (a), dorsal view. (b), lateral view of male. (c), cheliphore. (d), male oviger. (e), female oviger. (f), walking leg with enlargement of cement gland tube (g), setae on third coxa (h), and propodus with claw and auxiliary claws (i)

Abdomen long, extending ventrally from the thorax and covered with few spinules (Figs. 8a, 9f). Cheliphores with two-articled scape, first article longer than second article (Fig. 8c). Ultimate cheliphore article (movable finger) equipped with setose pad. Moveable digit slightly longer than fixed digit, its tip curved. Inner margins straight and joined when closed. Setae pad has a triangular shape of which half the length is attached to chela whereas other half protrudes. Single-articled, laterally placed palp represents the rudimentary state typical for the genus (Fig. 8b). It takes the form of an elongated bulb that is twice as long as wide. Female oviger composed of ten 

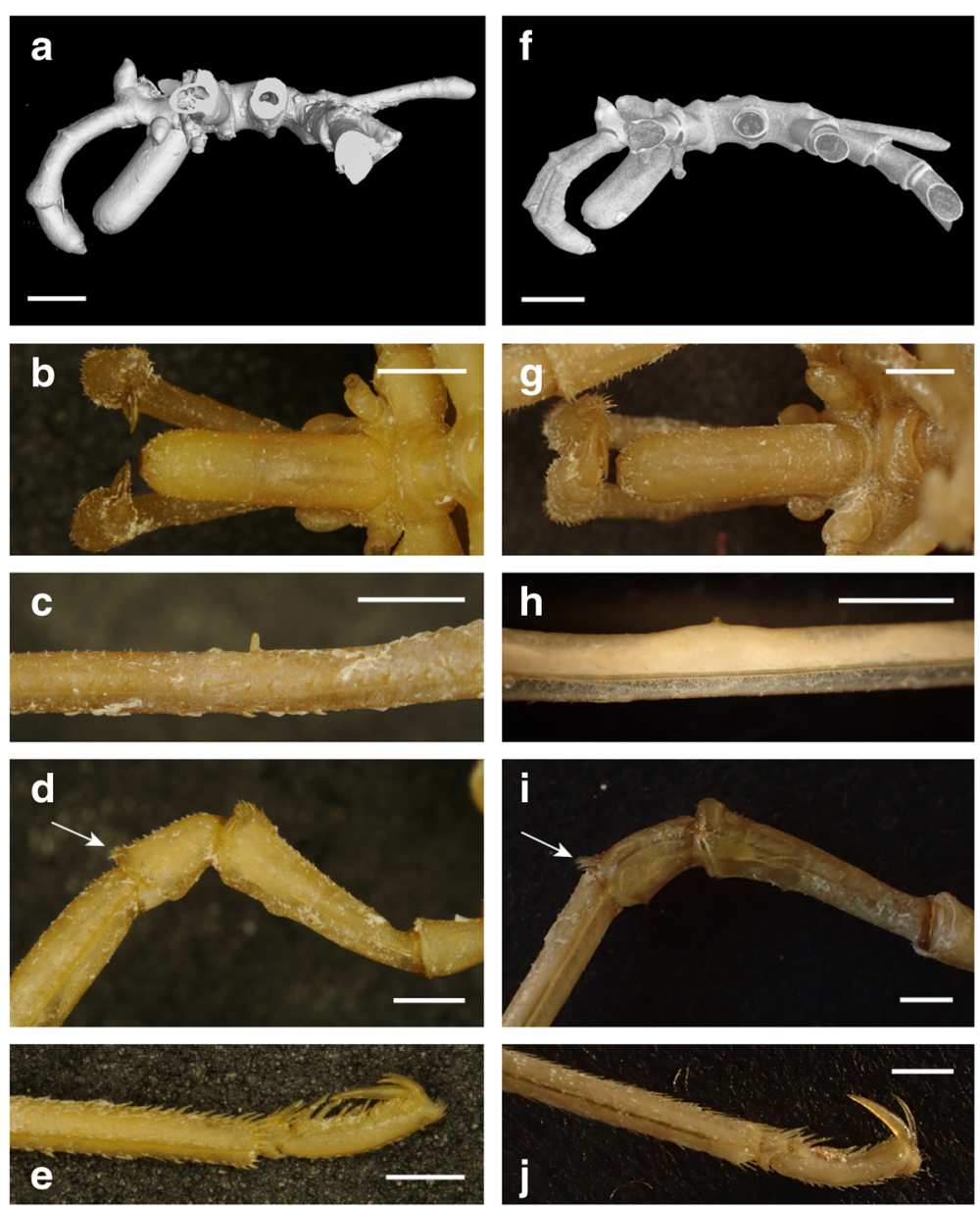

Fig. 9 Images of Pallenopsis aulaeturcarum sp. nov. Dömel \& Melzer (clade ANT_C) (a-e) and Pallenopsis obstaculumsuperavit sp. nov. Dömel (clade ANT_D) (f-j). a, f, micro-computed tomography $(\mu C T)$ of specimens in lateral view; scale bar $=2.5 \mathrm{~mm}$. b, $\mathbf{g}$, ventral view of proboscis; scale bar $=1.5 \mathrm{~mm}$. $\mathbf{c}$, $\mathbf{h}$, detail view of cement gland tube on femur (male); scale bar $=1.5 \mathrm{~mm}$. $\mathbf{d}$, $\mathbf{i}$, detailed view of coxae with setae on posterior margin of the third coxa (see arrow); scale bar $=1.5 \mathrm{~mm}$. e, j, propodus with claw and accessory claws; scale bar = 1.5 mm. $\mathbf{a}$, PS82_121_1; $\mathbf{b}, \mathbf{d}, \mathbf{e}$, PS82_156_2_1; c, PS82_185_1; f, JR287_152; $\mathbf{g}-\mathbf{j}$, JR287_124_3

articles (Fig. 8e). Proximal articles broaden slightly towards the distal part of each article. Second article longer, nearly twice the size of third article. Fourth oviger article more swollen and the longest of all. From fourth article onwards, article length decreases. Oviger articles are setose, with all setae pointing distally. Legs with several short setae (Fig. 8f,g). First and third coxa sub-equal. Second coxa about twice the length of third coxa. Assemblage of conspicuous setae on ventral side of second and third coxa, brush-like (Figs. 8h, 9i). Setae without bifurcation. Femur and first tibia about equal in size. Second tibia longest leg article. Tarsus is short and armed with one big spine on the ventral side nearer its distal part and a couple of smaller lateral spines. Propodus slightly curved, with three to four heel spines that differ insignificantly in length, but the distal spine is the largest (Figs. 8i, 9j). The remaining sole is covered with many shorter spines. Claw dorsally curved, its inner margin straight, its tip curved. Two auxiliary claws about one-half the length of main claw. Sexual pores on all second coxae on ventrodistal surface. In contrast to the male, the female lacks cement gland tubes (see below).

Measurements (holotype in $\mathbf{m m}$ ) Length of trunk (anterior margin of first trunk segment to distal margin of fourth lateral processes), 14.33; trunk width (across first lateral processes), 7.40; proboscis length, 6.35; abdomen length, 6.36; third right leg, coxa 1, 2.53; coxa 2, 7.59; coxa 3, 3.2; femur, 19.76; tibia 1, 15.91; tibia 2, 24.50; tarsus, 0.81 ; propodus, 4.43 ; claw, 2.46 ; auxiliary claws, 1.49 .

Different segments were measured in natural posture.

Male The general habitus and size of the male is similar to the female. Differences are in the sexual characters: oviger also ten-articled, typical for genus, but longer 
than female (Fig. 8d). Second articles longer, nearly twice the length of third article. Fourth and fifth articles the longest and equal in size. Distal articles more setose than proximal articles, with setae pointing in various directions. Small cylindrical cement gland tube is located in the center of the ventral side of the femur on top of a little swelling (Figs. 8g, 9h). It is as high as its diameter and points away from the podomere's surface in a nearly right angle. Sexual pores on ventral side of second coxae of third and fourth pair of legs.

Etymology The specific name obstaculumsuperavit stands for "the one that overcame (superare) the obstacle (obstaculum)". Pallenopsis obstaculumsuperavit has been reported from the Antarctic continental shelf and South Georgia, which are separated by deep sea representing a barrier for the dispersal of many brooding invertebrates.

Remarks This species belongs to the complex Pallenopsis patagonica s.l. defined in [26] and also analysed in [37]. In the previous studies, this species was defined as clade ANT_D or D, respectively.

\section{Combining morphological and genetic data}

There is a significant positive correlation of greater morphological distances with larger genetic distances for both genetic distances calculated based on COI $(r=0.36, p<0.0001$; Fig. 10a) and EOG sequences $(\mathrm{r}=0.51, \mathrm{p}<0.0001$; see figure provided in the Additional file 7). There is only a small difference between both correlations and SUB_2 has high intraspecific genetic distances between specimens from Burdwood Bank and the Falkland Islands or the Patagonian shelf (Additional file 7). When dividing the genetic COI distances, which are available for all morphologically analysed individuals, into ranges $(<2.5 \%=$ intraspecific; $>2.5 \%=$ interspecific $)$, the morphological distances are always higher for specimens that occur in allopatry than for those in sympatry. However, there is no significant difference between the genetic COI distance ranges, except for genetic distances above 10\% (Fig. 10b).

\section{Discussion}

Do genome-wide data add further information about previously unrecognised species diversity within the $P$. patagonica species complex?

We successfully used the target hybrid enrichment method, with baits designed for a different genus [22], to obtain an unprecedented data set to resolve the taxonomy and phylogeny of the Pallenopsis patagonica species complex. The genomic data enabled us to obtain better resolved and stronger supported branches in the phylogenetic tree in comparison to the mitochondrial tree published in [26]. In general, the topologies of the trees were similar except for the placement of the root, which was placed on the branch leading to clade Pallenopsis sp. ANT_N in the mitochondrial tree. Genomic data revealed that all clades from the Patagonian shelf, including SUB_4 and SUB_5 that were found to be paraphyletic with respect to the Antarctic clades in the mitochondrial tree, grouped together in the "Patagonian supergroup". In addition, Pallenopsis sp. ANT_N had a well-defined position within the "Patagonian supergroup" instead of being a sister taxon to all other species and clades of the P. patagonica species complex as in the previous analysis.

Most of the previously defined mitochondrial clades were well-separated in the multi-gene analyses with the exception of the two pairs of sister clades SUB_1/
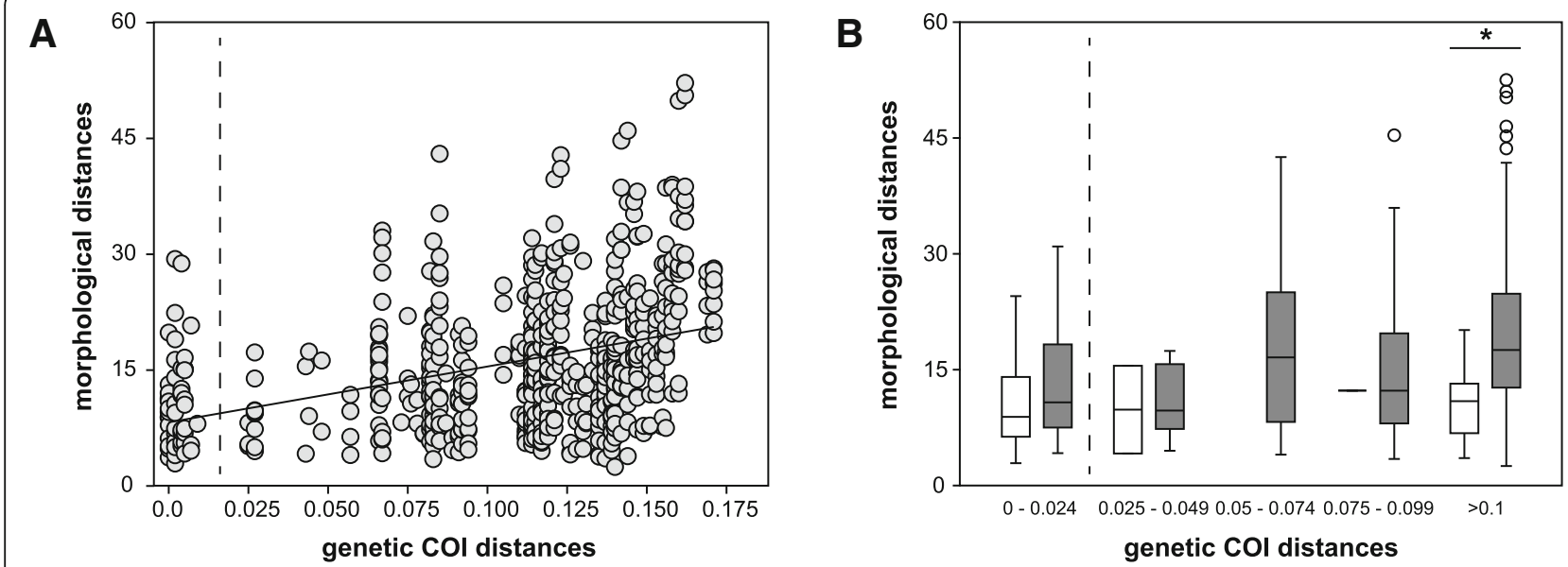

Fig. 10 Morphological against genetic distances. Morphological distances plotted against uncorrected genetic COI distances a) for each individual with regression line $(r=0.36, p<0.0001)$ and $\mathbf{b}$ ) for genetic ranges differentiated into sympatric (white) and allopatric (grey) samples of the Pallenopsis patagonica species complex. Dashed line separates intraspecific (left) and interspecific (right) genetic distances 
2 and SUB_4/5 (see table provided in Additional file 8 for an overview). It should be mentioned that the separation of these two pairs of clades was already put into question by the analysis of the ITS sequences in Dömel et al. [26]. There it was shown that specimens from Burdwood Bank (including one single specimen each from SUB_1 and SUB_2) grouped together, but had relatively large genetic distances. This disagreement with the mitochondrial clade assignment might be due to a mito-nuclear discordance, which has also been reported for the sea spider species complex Colossendeis megalonyx [20]. Although they were well-defined lineages in the phylogenetic tree, PCA and sNMF plots grouped both clades together. As morphological analyses also showed that there were no recognisable characters to distinguish SUB_1 and SUB_2, they should best be treated as one species. The differentiation between clades SUB_4 and SUB_5 was not supported by ITS data [26]. However, as no mito-nuclear discordance was found this could have been due to different mutation rates of the markers. The phylogenetic tree based on target hybrid enrichment revealed that SUB_4 is paraphyletic with respect to SUB_5, which may lead to the conclusion that this group originated on the Falkland Islands and subsequently migrated to the Patagonian shelf. Morphological data did not uncover characters to distinguish the two clades from each other and therefore support the hypothesis that they should still be considered as one species with geographical separation, as proposed by Dömel et al. [26]. Further intraspecific geographic separations were found for $P$. obstaculumsuperavit sp. nov. (ANT_D) and P. latefrontalis (ANT_F). For $P$. obstaculumsuperavit sp. nov. (ANT_D) a geographical differentiation has already been assumed between specimens from South Georgia and the Antarctic shelf based on the mitochondrial data set, but samples of P. latefrontalis (ANT_F) from Bouvet had not been analysed before. Geographic differentiation between populations from the Antarctic continental shelf and sub-Antarctic islands is known for other sea spiders [2, $25]$ as well as further benthic invertebrates $[54,79]$.

Principal component and phylogenetic tree analyses agreed with each other for all other predefined clades. But the cluster analysis showed similar proportions of ancestral populations for the closely related mitochondrial clades ANT_K (P. hiemalis, see below) and Pallenopsis sp. ANT_L together. However, the two clades were well separated in the phylogenetic tree and morphological analyses revealed several distinct characters between ANT_K and Pallenopsis sp. ANT_L. Therefore, we suggest that these clades represent two distinct species. Most likely, the relatively recent divergence of those two species in combination with a small sample size each $(n=3)$ represented an issue for the cluster analysis. Also, P. notiosa (SUB_3) clustered together with SUB_1/2 and again, this might be due to the small sample size especially of $P$. notiosa (SUB_3; $n=1$ ).

The results of our analysis also allow to discuss questions on the biogeographic history of the $P$. patagonica species complex. Unlike previous studies based on few genes $([81,37,26])$, our data clearly show a basal split between a Patagonian and an Antarctic group, whose distributions overlap only in South Georgia. As only little is known about the phylogeny of Pallenopsis as a whole and as we do not know exactly which species are the closest relatives of the $P$. patagonica species complex, we cannot assess whether the complex originated within Antarctica or not. However, the Antarctic supergroup shows a pattern of a relatively rapid radiation as opposed to the Patagonian supergroup which demonstrates earlier divergences. This pattern might be due to a rapid radiation after colonisation of the Antarctic, therefore supporting a non-Antarctic origin of the complex.

\section{Do we find morphological characters to distinguish the independently evolving lineages of the $P$. patagonica species complex and formally describe new species?} Using the key for Pallenopsis [82] from [13], we would characterize all specimens analysed as $P$. patagonica. This key, however, only includes nine out of 18 Antarctic and sub-Antarctic species [62]. The key given by Pushkin [69] for ten Pallenopsis of the Southern Ocean is misleading and would assign none of the analyzed specimens to $P$. patagonica. A recent attempt to update the identification key for Antarctic and sub-Antarctic Pallenopsis including all species was performed by Cano-Sánchez and López-González [9]. Still, not all specimens can be assigned correctly to species level. An example is $P$. patagonica (SUB_1/2/4/5), for which the lateral processes do not touch each other (but see [81]).

Morphometric analyses aiming at separating clades were challenging because of limited sample size. In addition, little is known regarding allometric growth in Pallenopsis and regression analysis was not possible for the same reason of not having sufficient numbers of individuals of both sexes for each clade [56]. Nevertheless, the simpler approach of taking relative lengths of morphological structures coupled with character selection for discriminant analysis showed that the species can be satisfactorily separated using a small number of characters with the relative values having better performance in species discrimination. The leg span best represents the actual body size of a sea spider and would have been the preferred reference length but analyses revealed cases of re-grown legs in the data set. 
Hence, relative values were expressed as proportions relative to the trunk lengths.

Diagnostic characters for at least nine species within the $P$. patagonica species complex, of which five have already been described, were found (see table provided in Additional file 8 for an overview). Additionally, Weis et al. [81] stated that P. macneilli a species found in Australian waters and hence was not included in this study, was also part of the $P$. patagonica species complex based on COI data. In general, the morphological distinction between genetic clades is clearer for the Antarctic ones. Weis et al. [81] already found out that the "Antarctic supergroup" consist of two described species, $P$. buphtalmus and P. latefrontalis. Furthermore, Weis et al. [81] mentioned that one specimen (PpaE002) stood out due to its horizontally positioned abdomen, in comparison to the common upwards oriented abdomen seen in most specimens. The above-mentioned individual has been genetically identified as $P$. obstaculumsuperavit $\mathrm{sp}$. nov. (ANT_D). In fact, the position of the abdomen is a diagnostic character for this newly described species. The individual mentioned in Weis et al. [81] was reinvestigated and it can be confirmed that the horizontal position of the abdomen described before is actually downwards oriented, too.

P. aulaeturcarum sp. nov. (ANT_C) shares many morphological characters with other clades of the "Antarctic supergroup", e.g. spinules on dorsal and ventral surface of the trunk, ratio of claw to accessory claw and propodus, and length of second coxa in relation to the sum of the first and third coxa. It should be stressed that the morphological differentiation would not have been recognised without the knowledge of the genetic background information thus highlighting once again the benefits of an integrative approach.

Cano-Sánchez and López-González [9] recently described two new species from Victoria Land (Ross Sea), P. gracilis Cano-Sánchez \& López-González, 2019 [9] and P. rotunda Cano-Sánchez \& López-González, 2019 [9]. Both can be distinguished from P. obstaculumsuperavit sp. nov. (ANT_D) by their upwards oriented abomina. Characters disagreeing with $P$. aulaeturcarum sp. nov. (ANT_C) are the lateral processes that are closer together, even touching, in P. rotunda and the forward pointing ocular tubercle of $P$. gracialis.

Specimens from the "Patagonian superclade" were morphologically very similar. In fact, SUB_1/2 and SUB_4/5 look alike and cannot be distinguished morphologically. If we were to consider the morphological result only, we would probably assign those clades to a single species. Strangely enough, within the phylogenetic tree $P$. notiosa (SUB_3), a well-defined species and Pallenopsis sp. ANT_N are placed between SUB_1/2 and SUB_4/5. Hence, SUB_1/2 and SUB_4/5 can be considered as cryptic but not sister species, a phenomenon that has also been observed, e.g. in nematodes [77].

Only two individuals from Shag Rocks (south of the Antarctic Polar Front) were available for Pallenopsis sp. ANT_N and therefore it was designated as an Antarctic clade by Dömel et al. [26]. Also morphologically, the two individuals were very similar to the Antarctic species (i.e. the distance between the lateral processes is about aslong as their diameter and the palps are longer than their diameter). However, phylogenetically, these specimens fell outside the Antarctic radiation and belonged to the "Patagonian supergroup". Furthermore, during more detailed examination of these specimens, bifurcated setae, which are supposed to represent complex structures [52] with potential for species-specific features and (even if not as prominent) correspond to the character of the Patagonian species $P$. yepayekae, were detected on the second and third coxa. In fact, Weis et al. [81] described these setae as a unique character of specimens from the Chilean clade (i.e. P. yepayekae), and hence a character that can be used to distinguish it from specimens from the Antarctic region or the Falkland Islands. There were two species that were of particular interest, because they partly matched the characteristics of Pallenopsis sp. ANT_N: P. tumidula [55] and P. candidoi [60]. Both seemed to exhibit the short setae on the ventral side of the second and third coxa. The latter occurs from South Georgia to South Brazil and hence has a geographical overlap with Pallenopsis sp. ANT_N. Pallenopsis candidoi can be distinguished from $P$. patagonica s.s. and $P$. yepayekae by the eight-articled oviger in females, and by the auxiliary claws being clearly longer than half the lengthof the main claw [81]. The two individuals included in this study were males and no prediction can be made regarding the female ovigera, but the auxiliary claw isapproximately half the length of the main claw, rather than longer. Pallenopsis tumidula was characterised and drawn by Stock [75] with so-called 'Fiederdornen' (German for pinnated spine) on the ventral-distal side of the second and third coxa. He mentioned that this feature made $P$. tumidula clearly distinguishable from $P$. patagonica. Confusingly, in the original description of 1923, Loman neither mentioned short setae on the coxa nor depicted them in his drawings. Also, the originaldescription states that the lateral processes are separated by about half their diameter, which is smaller than those displayed by the studied specimens. However, due tothe small sample size, we refrain from designating this clade as a new species.

\section{Reinstallment of P. hiemalis}

Specimens assigned to clade ANT_K differed from the others in having a straight rather than curved propodus. 
Also, the lateral processes had a dorso-distally located crowning of up to three pointy tubercles that differs from the frequently occurring but much smaller thickenings. Those characters have also been described for $P$. hiemalis by Hodgson [40] and Pushkin [68, 69]. However, this species has been synonymised with $P$. patagonica by Child [13]. Cano-Sánchez and López-González [9] already suggested that $P$. hiemalis is a valid species, however this statement was made without any morphological reinvestigation. There are indeed characters in the original description of $P$. hiemalis that do not fit $P$. patagonica s.s. but are characteristic for Antarctic specimens of the species complex (e.g. "[...] lateral processes rather widely separated" and "Palps, a rather long stump"). Parts of the description that militate against ANT_K specimens being P. hiemalis concern the size of the second coxa, i.e. "[...] second [coxa] is fully twice as long as the other two together" [40]. This, however, is an uncommon ratio for Pallenopsis and also does not match the description of $P$. patagonica s.s. Hence, this might be a mistake due to a combination of the following phrasings: i) "[...] second [coxa] is twice as long as first or third coxa" and ii) "[...] second [coxa] is fully as long as the other two together". The descriptions of P. hiemalis by Hodgson [40] and Pushkin [68] differ in their described characters, too. An example of this discordance is the description of a very prominent character of specimens from ANT_K which display three distinct tubercles on the dorsal-distal side of the lateral processes. Those were described as "tricipital tubercles" in Pushkin [68] but a single "stout tubercle of no great elevation" was described by Hodgson [40]. As Hodgson's description is based on a single specimen, the missing character might be explained by a variation of attributes due to developmental stages. However, the few measurements given in Hodgson [40] indicate that the individual was full-grown. We herein propose to reinstall $P$. hiemalis [40] as autonomous species and refer to the species description in Pushkin [68]. Pallenopsis hiemalis belongs to Pallenopsis patagonica s.l. defined in [26] and also analyzed in [37]. In the previous studies, this species was referred to as clade ANT_K or K.

\section{Which species is $\mathrm{P}$. patagonica s.s.?}

The original description of $P$. patagonica [42] agrees with the morphology of the specimens from clades SUB_4 (Falklands) and SUB_5 (Patagonia). Previous analyses revealed that those two clades can be distinguished with the mitochondrial COI but not with the nuclear ITS marker [26]. Further morphometric and morphological analyses detected no distinguishable characters and also the multi-marker analyses revealed that SUB_4 and SUB_5 can be considered as one species. Specimens of SUB_1/2 are very similar to those of SUB_4/5 and as the location of the type material of $P$. patagonica s.s. cannot be defined because the original description records specimens from three different locations in Patagonia $\left(46^{\circ} 53^{\prime} \mathrm{S} 75^{\circ} 11^{\prime}\right.$ $\mathrm{W}, 50^{\circ} 10^{\prime} \mathrm{S} 74^{\circ} 42^{\prime} \mathrm{W}$, and $\left.52^{\circ} 20^{\prime} \mathrm{S} 68^{\circ} 0^{\prime} \mathrm{W}\right)$ where both species (SUB_1/2 and SUB_4/5) occur, it is difficult to decide which one represents $P$. patagonica s.s. A correct assignment of the species name $P$. patagonica to a genetic clade would therefore necessitate a genetic re-examination of the type series, which may not be obtainable from such old material.

\section{Polar gigantism}

The phenomenon that Antarctic specimens are unusually large is commonly known as polar gigantism [10]. The morphometric analyses revealed that all specimens within the Antarctic Polar Front are significantly larger than the Patagonian ones. This could have been biased by the fact that males dominated in sub-Antarctic and females dominated in Antarctic specimens. Size differences between male and female with the latter being the larger ones have been reported for many species [4], however dimorphism did not seem to influence our results.

Morphometric analyses alone would probably have led to incorrect conclusions regarding the phylogenetic position as one would have probably assumed that Pallenopsis sp. ANT_N is more closely related to the "Antarctic superclade". However, looking at Pallenopsis sp. ANT_N in more detail, we detected bifurcated setae on the second and third coxa, which (even if not as prominent) is very similar to the character of the Patagonian species $P$. yepayekae. This can be seen as evidence for at least two independent events of polar gigantism within the genus Pallenopsis.

\section{Do we find evidence for adaptive divergence at morphological or genetic levels or do neutral evolutionary processes suffice to explain the observed species diversity?}

Target hybrid enrichment can be used to specifically target coding regions and hence is a useful technique to test a large number of genes for selection [43]. For the $P$. patagonica species complex, only a few genes were found to be under selection. In addition, no branch under selection was detected and delineation due to selection pressure on any of the detected genes can be excluded. However, the bait set used here was not tailored to $P$. patagonica but was based on a transcriptome of the Southern Ocean sea spider Colossendeis megalonyx. Whereas for C. megalonyx all bait regions were recovered [22], for the $P$. patagonica species complex on average only $30 \%$ (max. of $35 \%$ ) of all bait regions were successfully enriched. Most likely those loci represent 
well-conserved genes that show relatively little variation across families or genera of sea spiders and recently evolved genes that could have been of further relevance were not analyzed within this study.

Furthermore, there is no clear evidence for selection when analyzing morphological and genetic data together. In the case of sympatric speciation and adaptation to different ecological niches, one would expect high morphological differences also for recently diverged species, i.e. genetic distances just above $2.5 \%$, and especially when they occur in sympatry (ecological character displacement). This does not appear to be the case in the $P$. patagonica species complex, because regardless of whether the species occur in sympatry or not, morphological distances were similarly high throughout the range of genetic distances. Only at very high genetic distances, for specimens living in allopatry morphological distances were significantly higher than for specimens living in sympatry. At the same time, specimens from the same area tended to be more similar to each other among species, which may be explained by their similar adaptations to the same environment.

Among the characters which were found to contribute to species separation we find some with potential ecological significance (like the absolute and relative length of the proboscis and first cheliphore article), which might indicate the existence of differences in food preferences between the species. The proboscis is known to have a diverse range of shapes and sizes among sea spiders indicating differences in feeding strategies [21, 80], but also the cheliphores can be relevant features as they are used to capture or cut the prey [4]. Yet, these characters are accompanied by other ones with supposedly little or no role in ecological differentiation. We might thus tentatively hypothesize that minor ecological differences between the species do exist, but they reflect local adaptation or even non-selective variation, since no character displacement in sympatry is observed. Especially species that occur in sympatry were expected to form different ecological niches. As the Antarctic continental shelf is relatively uniform in terms of geological structures and large regions that have been influenced by grounded ice shelfs or even iceberg ploughing are plain and dominated by gravel, food sources seem to be a major cause for specialisation. As this does not seem to be the case in the P. patagonica species complex, this might indicate that there is no competition for food. Jones [44] found a similar case were four species of the Jaera albifrons group (Crustacea; Isopoda) displayed identical mouthparts although they occurred in sympatry and concluded that food was not an isolating factor. It does not appear to be the case that the scarce morphological characters that differentiate the species of the complex, like position of the abdomen, distances between the lateral processes or shape of the setae patch on the cheliphores are of significant biological relevance and hence could be subject to selection.

\section{Conclusion}

Combining genome-wide molecular sequence data with extensive morphological and morphometric analyses, we generated an unprecedented data set for members of the $P$. patagonica sea spider species complex. We established a well-resolved phylogeny based on target hybrid enrichment data and delineated species boundaries within the taxonomically difficult group which led to the reinstallment of $P$. hiemalis as well as the description of two new species, namely $P$. aulaeturcarum and $P$. obstaculumsuperavit. Contrary to previous studies, our results supported the division of the species complex into an Antarctic and a Patagonian group. Concerning speciation processes, our data supports the hypothesis of speciation in independent glacial refugia, as we found no consistent evidence for adaptive divergence. The latter aspect, however, can only be answered conclusively when more specimens from the different lineages and areas as well as more genomic loci become available.

\section{Methods \\ Material}

A subset of specimens already included in Dömel et al. [26] was studied including individuals from the Antarctic continental shelf and the shelf of sub-Antarctic islands, the Falkland Islands and Patagonia (Fig. 11) (for further details of sampling and storage see [26]). Up to three individuals per species or clade were analyzed. For morphological measurements, 37 specimens were used. For genetic analyses, more samples of three lineages (ANT_C, ANT_D, P. latefrontalis (ANT_F)) with Antarctic distribution ranges were included and additional samples of P. latefrontalis (ANT_F) from Bouvet Island were added to improve the geographical coverage. Hence, the final genetic dataset consisted of 62 individuals of the $P$. patagonica species complex and a single individual of $P$. pilosa [42] as an outgroup (Table 3).

\section{Bait enrichment}

For genetic analyses, a target hybrid enrichment approach was chosen. For the present analyses we used the bait set designed in Dietz et al. [22] using the workflow described by Mayer et al. [59]. Briefly, the baits were constructed based on an assembly of transcriptomic data of the sea spider Colossendeis megalonyx and included a total number of 12,014 baits covering 3682 bait regions 


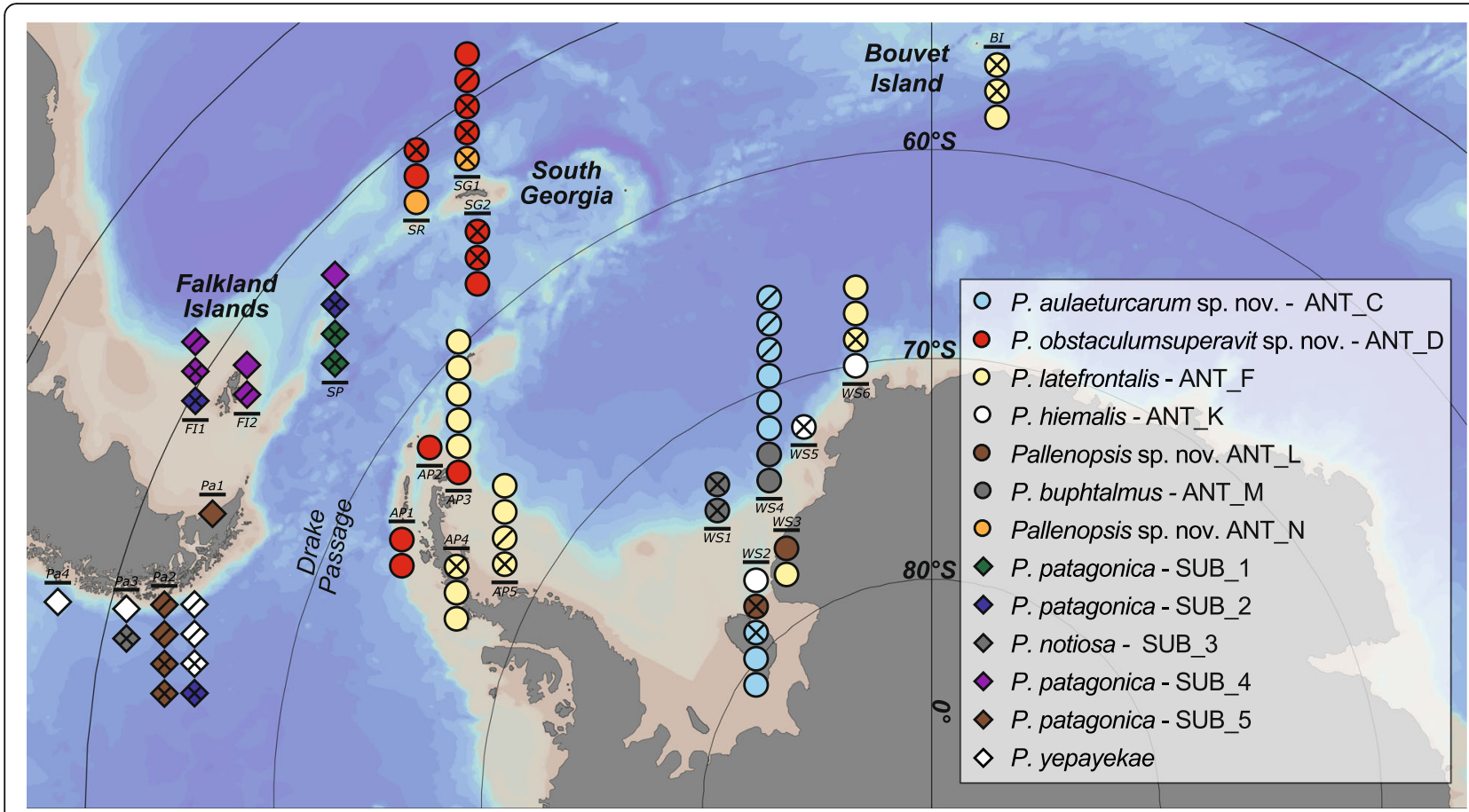

Fig. 11 Specimen map. Sampling sites of Antarctic, sub-Antarctic and Patagonian specimens of the Pallenopsis patagonica species complex and their assignment to species or mitochondrial clades. Each symbol below or above the line and locality ID represents one specimen. Different clades are represented by different symbols/colors. Analysis methods are indicated for each individual within a symbol (slash: morphological analyses only; no indication: genetic analyses only; cross: genetic and morphological analyses)

from 1607 single-copy EOGs present in all spider genomes. See Dietz et al. [22] for details and bait sequences. Baits were manufactured by Agilent Technologies (Waldbronn, Germany).

Sample preparation was conducted following a slightly modified version of Agilent's protocol "200 ng DNA sample" for "Agilent's SureSelect Target Enrichment System". A detailed written protocol is provided in Additional file 9, Protocol 1. After the enrichment steps, samples were pooled in equimolar ratios for sequencing. Two pools were prepared, containing 32 samples each. Libraries were sent to GATC Biotech GmbH (Konstanz, Germany) for sequencing on an Illumina MiSeq platform using the V2 $2 \times 250$ bp paired-end sequencing kit. 5\% PhiX spike-in was added to each run to increase sequencing diversity and hence improve the signal of sequences. Upon delivery, the NGS reads were adapterand quality-trimmed with fastq-mcf r. 488 [5]. The raw data are available from NCBI Sequence Read Archive (BioProject ID PRJNA544606). We used two complementary approaches to construct data sets, SNP and EOG, from the reads for different purposes. The SNP approach was used to call variants of different sample sets and also include flanking regions. The EOG approach is solely based on orthologous regions and hence is supposed to cover genes only.

\section{SNP analyses}

As there is no reference genome for sea spiders available, a de novo reference based on all raw reads from the samples of the $P$. patagonica species complex was generated with a pipeline of custom Bash shell scripts including quality filtering, sequence editing and assembly. Further information is provided in Additional file 9, Protocol 2. SNPs were called separately for three different data sets: i) all samples belonging to the $P$. patagonica species complex, ii) P. patagonica samples belonging to the "Patagonian supergroup", and iii) P. patagonica samples belonging to the "Antarctic supergroup"; see results section for group assignment) to maximize the number of group-specific SNPs (see Additional file 9, Protocol 3 for more information). To analyse the genetic structure, PCAs were conducted using the R-package SNPRelate v. 1.12.2 [85] with default parameters. sNMF-plots were calculated to investigate the number of genetic clusters within the dataset, using the LEA package v. 2.0.0 [31]. A range of $\mathrm{K}$ values (number of ancestral populations) in the interval of 1-20 were tested. The number of repetitions was set to 40 with 40,000 iterations and the lowest cross-entropy per $\mathrm{K}$ value was determined and plotted to choose the most likely $\mathrm{K}$ value. To also analyze the relationships between clusters, a maximum likelihood tree based on the SNP data was obtained with SNPhylo v. 20,140,701 [50]. 


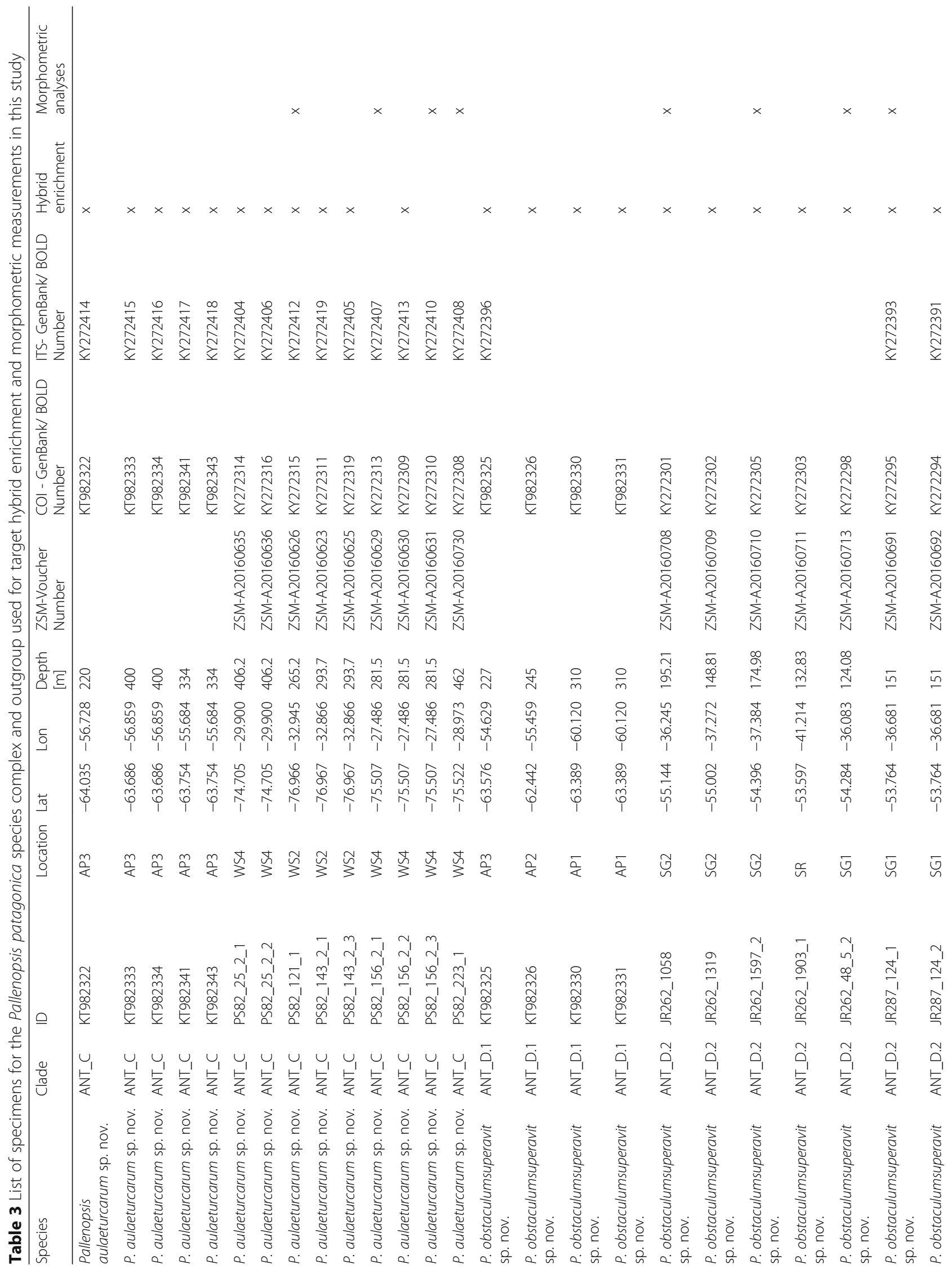




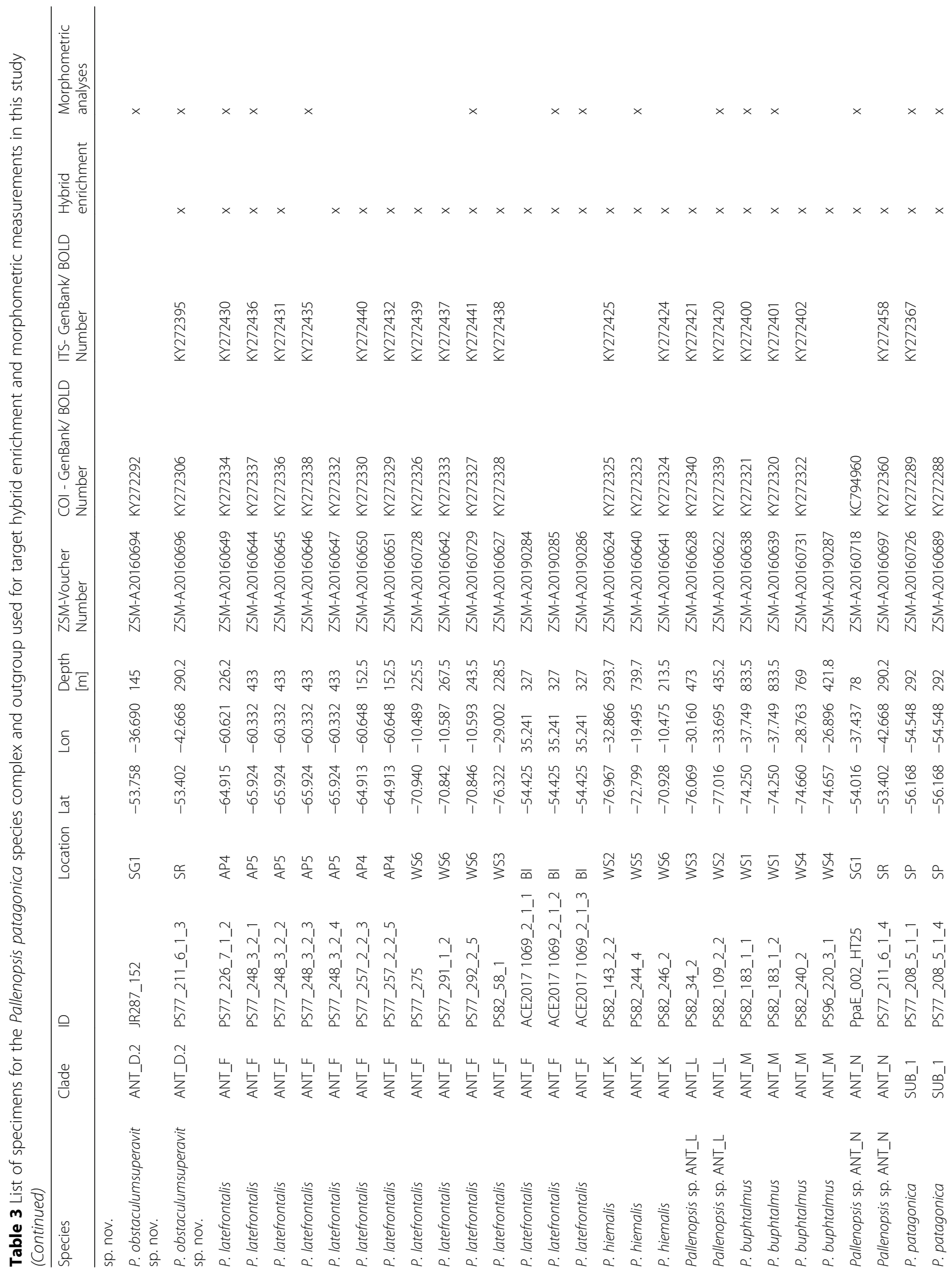




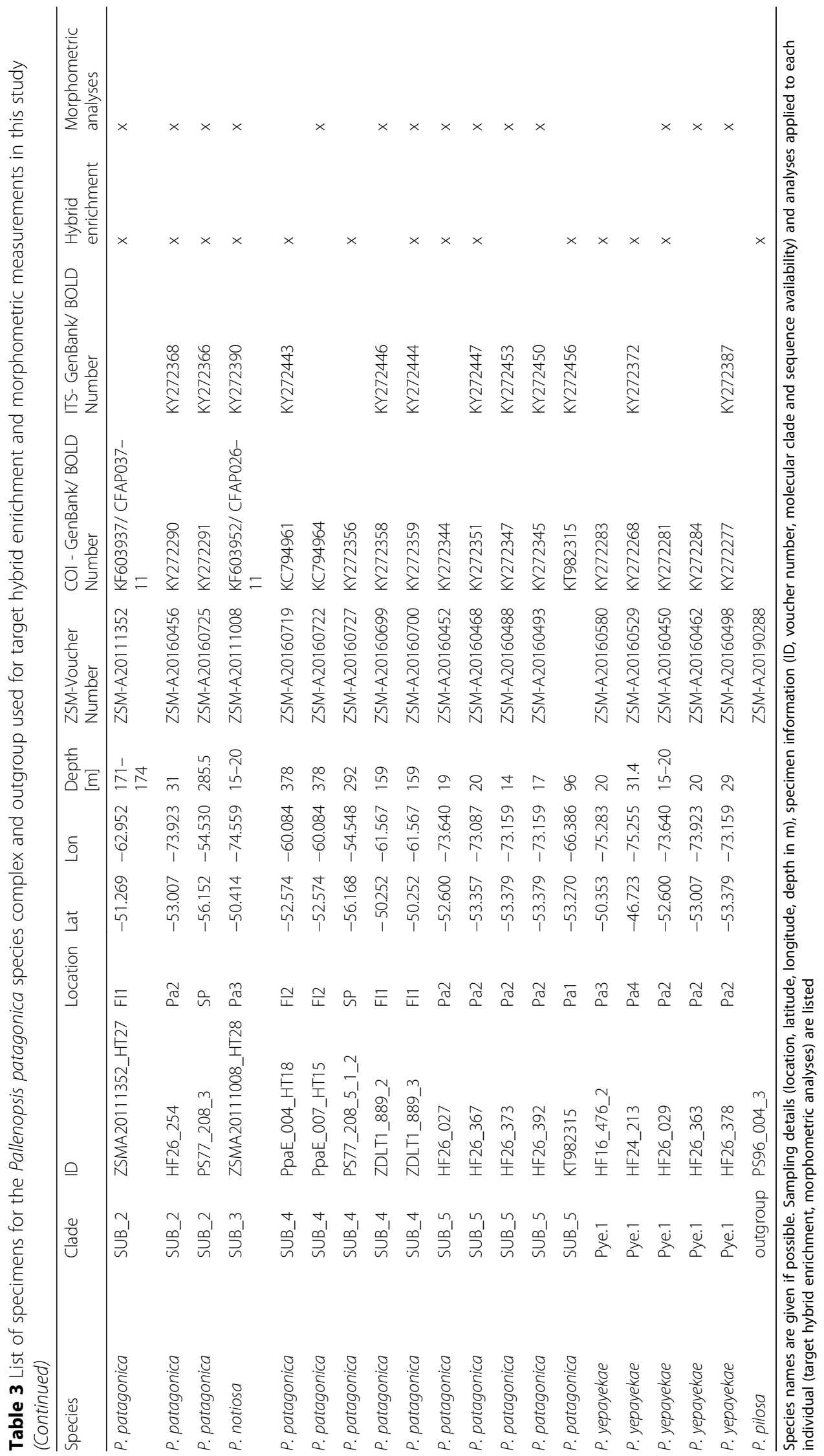




\section{Orthology assignment and phylogenetic analyses}

For the bait construction, Dietz et al. [22] had searched OrthoDB 9.1 [84] for orthologous single-copy genes present in all four spider (Araneae) genomes. Using Orthograph v. 0.5.14 [67] these genes were aligned on the amino acid level and hidden Markov models (HMMs) were created. With the aid of Orthograph, these HMMs were then reused to mine the transcriptome of $P$. patagonica for the EOGs of interest, as was previously done for C. megalonyx [22]. As the baits were originally designed for Colossendeis, the Pallenopsis genes were aligned with their Colossendeis homologs using MAFFT v. 7.305b [46]. Regions that were aligned to the Colossendeis bait sequences and which were at least $30 \mathrm{bp}$ in length were extracted. The trimmed Illumina reads were mapped against these regions with the BWA-MEM algorithm in bwa v. 0.7.17 (available from: https://sourceforge.net/projects/biobwa/files). Default parameters were used, except that the minimum match length was set to $30 \mathrm{bp}$. Successfully mapped reads were mapped again against the full coding sequences from the corresponding contigs with bwa as described above. Diploid consensus sequences of the regions matching the reference were generated for each specimen with samtools v. 1.6 [53] and bcftools v. 1.6 (available from: https:/github.com/ samtools/bcftools). As the consensus sequences were already aligned to the reference sequence, no further alignment was necessary and all sequences were already in the correct reading frame. All gene alignments were then concatenated to one supermatrix of nucleotide sequences, which was used in a maximum likelihood phylogenetic analysis with IQ-TREE v. 1.5.4 [66]. The alignment was partitioned by codon positions and the optimal partitioning scheme was selected with an algorithm implemented in ModelFinder [11, 45] using the Bayesian Information Criterion. A phylogenetic tree search was conducted with IQ-TREE using the selected models, and branch support values were determined from 1000 ultrafast bootstrap replicates.

For rooting the tree, we mined the published transcriptome of Anoplodactylus insignis (NCBI accession number SRX2544807) for the genes of interest using Orthograph with the same procedure as described above. Anoplodactylus insignis belongs to the Phoxichilidiidae, a family thought to be related to the Pallenopsidae [3, 71]. Amino acid sequences of $A$. insignis were added to the translated genes alignments with MAFFT using the -add option. EOGs for which no A. insignis sequence was found and positions present in less than $50 \%$ of the taxa were removed. Outlier sequences were excluded with the OLIinSeq program by CM (available upon request) as described in Dietz et al. [22]. After the root of the tree was determined, further analyses were carried out with the nucleotide data sets excluding $A$. insignis.

\section{Selection tests}

Comparative sequence analyses based on stochastic evolutionary models within HyPhy v. 2.3.13 [47] were used to test for selection. The alignment described in the previous section excluding $A$. insignis was used, additionally filtering out all positions present in less than $50 \%$ of the samples. All analyses were based on the phylogenetic tree obtained with IQ-TREE (see above), as we expect all genes to have evolved according to the same phylogeny. Furthermore, either the default or settings recommended by the authors of the programs were used. FUBAR [63] and MEME [65] were used to test for selection across sites. Genes with codons under selection (FUBAR: pp. $\geq 0.99$; MEME: $p \leq 0.01$ ) that were recognised with both methods were used for further branch-site tests, namely, aBSREL [73] and BUSTED [64]. Here, both terminal and internal branches were tested.

\section{Morphology}

Specimens from the different mitochondrial clades of the $P$. patagonica species complex were studied using light microscopy and $\mu \mathrm{CT}$. For identification, preparation and analyses of individuals, Leica DMRD and Leica DM5000B microscopes were used. Accurate pictures were taken using the Olympus Stylus TG-4 camera (Microscope mode for automatic generation of extended depth of field images). To obtain a 3D reconstruction of one individual per clade without damaging the specimen, a Phoenix Nanotom (GE Sensing \& Inspection Technologies, Wunstorf, Germany) cone beam CT scanner was used at voltages of $80 \mathrm{kV}$ to $120 \mathrm{kV}$ and currents of 90 to $140 \mu \mathrm{A}$ for $53 \mathrm{~min}$. 1440 radiographs were saved and analysed with the integrated software and VGStudio Max v. 2.2.2 (64 bit; Isosurface and Volume Rendering).

Morphometric body measurements were carried out using the digital caliper from MarCal IP67 (Mahr Metrology, Germany). Measurements follow those applied by Dietz et al. [23, 24], with a focus on characters evaluated as useful for species delimitation, and characters that are potentially linked to fitness differences. The latter include i) the proboscis with terminal mouth, which takes up and processes food; ii) the cheliphores, which function as devices to hold the prey/food and moving it to the mouth opening; and iii) the walking legs. When all limbs were present, up to 135 measurements per specimen were taken (Table 4). However, due to damage during trawling, transport, storage or preceding genetic analysis, distal leg articles were often missing and as a result, not all limbs could be measured. Due to the bilateral symmetry of the body, the averaged measurements of the left and 
Table 4 List of characters measured for morphometric analyses

\begin{tabular}{|c|c|}
\hline Abbreviation & Description \\
\hline trunk L & total length of trunk \\
\hline ceph. segment & length of cephalic segment \\
\hline trunk W1 & $\begin{array}{l}\text { diameter of lateral process of } 1 \text { st } \\
\text { trunk segment }\end{array}$ \\
\hline trunk W12 & $\begin{array}{l}\text { width of trunk between 1st and } \\
\text { 2nd lateral processes }\end{array}$ \\
\hline trunk W2 & $\begin{array}{l}\text { diameter of lateral process of } \\
\text { 2nd trunk segment }\end{array}$ \\
\hline trunk W23 & $\begin{array}{l}\text { width of trunk between } 2 \text { nd and } \\
\text { 3rd lateral processes }\end{array}$ \\
\hline trunk W3 & $\begin{array}{l}\text { diameter of lateral process of } 3 r d \\
\text { trunk segment }\end{array}$ \\
\hline trunk W34 & $\begin{array}{l}\text { width of trunk between } 3 \text { rd and } \\
\text { 4th lateral processes }\end{array}$ \\
\hline trunk W4 & $\begin{array}{l}\text { diameter of lateral process of } 4 \text { th } \\
\text { trunk segment }\end{array}$ \\
\hline trunk $\mathrm{H}$ & height of trunk \\
\hline abdomen $\mathrm{L}$ & length of abdomen \\
\hline abdomen W & width of abdomen \\
\hline ocular tubercle $\mathrm{H}$ & height of ocular tubercle \\
\hline ocular tubercle W & width of ocular tubercle \\
\hline eye $\mathrm{H}$ & height of anterior eye \\
\hline forehead $\mathrm{H}$ & $\begin{array}{l}\text { distance between eyes and apex } \\
\text { of ocular tubercle }\end{array}$ \\
\hline eyes distance & distance between eyes \\
\hline proboscis $L$ & proboscis length \\
\hline proboscis basis & $\begin{array}{l}\text { diameter of proboscis at proximal } \\
\text { basis }\end{array}$ \\
\hline proboscis thickest & $\begin{array}{l}\text { diameter of proboscis at thickest } \\
\text { part of proboscis }\end{array}$ \\
\hline proboscis thick2tip & $\begin{array}{l}\text { distance between tip of proboscis } \\
\text { and thickest part }\end{array}$ \\
\hline proboscis thinnest & $\begin{array}{l}\text { diameter of proboscis at thinnest part } \\
\text { of proboscis }\end{array}$ \\
\hline proboscis thin2tip & $\begin{array}{l}\text { distance between tip of proboscis and } \\
\text { thinnest part }\end{array}$ \\
\hline I/r palp & length of palp bulb \\
\hline I/r cheliphore 1-3 & $\begin{array}{l}\text { length of first } 3 \text { cheliphore articles; } \\
\text { left and right }\end{array}$ \\
\hline I/r cheliphore 4 & $\begin{array}{l}\text { ultimate cheliphore article } \\
\text { (moveable finger) }\end{array}$ \\
\hline I/r oviger $1-10$ & $\begin{array}{l}\text { length of all } 10 \text { ovigeral articles; } \\
\text { left and right }\end{array}$ \\
\hline I/r WL1-4 coxa1 & $\begin{array}{l}\text { length of } 1 \text { st coxa for all } 4 \text { pairs of } \\
\text { walking leg; left and right }\end{array}$ \\
\hline I/r WL1-4 coxa2 & $\begin{array}{l}\text { length of } 2 \text { nd coxa for all } 4 \text { pairs of } \\
\text { walking leg; left and right }\end{array}$ \\
\hline I/r WL1-4 coxa3 & $\begin{array}{l}\text { length of 3rd coxa for all } 4 \text { pairs of } \\
\text { walking leg; left and right }\end{array}$ \\
\hline I/r WL1-4 femur & $\begin{array}{l}\text { length of femur for all } 4 \text { pairs of walking } \\
\text { leg; left and right }\end{array}$ \\
\hline
\end{tabular}

Table 4 List of characters measured for morphometric analyses (Continued)

\begin{tabular}{|c|c|}
\hline Abbreviation & Description \\
\hline$\overline{\mathrm{I} / \mathrm{r} \text { WL1-4 tibia1 }}$ & $\begin{array}{l}\text { length of 1st tibia for all } 4 \text { pairs of } \\
\text { walking leg; left and right }\end{array}$ \\
\hline I/r WL1-4 tibia2 & $\begin{array}{l}\text { length of } 2 \text { nd tibia for all } 4 \text { pairs of } \\
\text { walking leg; left and right }\end{array}$ \\
\hline I/r WL1-4 tarsus & $\begin{array}{l}\text { length of the tarsus for all } 4 \text { pairs of } \\
\text { walking leg; left and right }\end{array}$ \\
\hline I/r WL1-4 propodus & $\begin{array}{l}\text { length of the propodus for all } 4 \text { pairs } \\
\text { of walking leg; left and right }\end{array}$ \\
\hline I/r WL1-4 claw & $\begin{array}{l}\text { length of the claw for all } 4 \text { pairs of } \\
\text { walking leg; left and right }\end{array}$ \\
\hline I/r WL1-4 aux. claw & $\begin{array}{l}\text { length of auxiliary claw for all } 4 \text { pairs } \\
\text { of walking leg; left and right }\end{array}$ \\
\hline
\end{tabular}

Description of how characters were measured and abbreviations for all as used in Table 3 and Additional file 4

right appendages (legs, palps and cheliphores) were used to reduce the amount of missing values. Ovigeral articles, which are appendices specific to sea spiders and used by males to carry fertilised eggs, were excluded from further analyses, to avoid a bias caused by sexual dimorphism.

For analyses of morphometric measurements Past v. 3.18 [36] was used. First, measurements were tested for normality distribution using the Anderson-Darling, Shapiro-Wil, and Jarque-Bera tests. PCAs were performed to visualise the clustering of specimens regardless of predefined clades and missing values were handled as "iterative imputation" as recommended in Past Manual [35]. In addition, row-wise bootstrapping was carried out using $N=1000$. Also, LDAs was performed and confusion matrices calculated.

To cope with the missing data points and to limit the analysis to clades with a minimal representation, we pre-filtered the data set to leave only clades with a minimum of three individuals and characters with not more than $10 \%$ missing values. Remaining missing values were imputed using Predictive Mean Matching. Analyses were performed using both absolute values of measurements, and relative lengths of measurements expressed as proportion of the trunk to reduce biases caused by different absolute sizes.

Since the number of the characters was large with respect to the number of the individuals, a selection of characters for LDA was performed to avoid model overfitting. The heuristic search for the optimal sets of characters was carried out by iteratively using the stepclass function from the $\mathrm{R}$ package klaR $\mathrm{v}$. $0.6-14$ with forward-backward selection direction, cross-validation correctness rate as the optimality criterion (taking ten folds) and 5 as the maximum number of characters in a set. The search was organised by picking each one of the characters as starting variable and repeating the procedure 
ten times. The performance of the character sets was recorded and the best set was used for a final LDA.

Finally, nonparametric unifactorial Kruskal-Wallis $\mathrm{H}$ in combination with Dunn's post hoc test (Bonferroni-corrected) were used to test for significant differences between geographic (sub-Antarctic vs Antarctic) and genetic groupings as well as sexes.

\section{Combining morphological and genetic data}

To test whether there are greater morphological differences for taxa living in sympatry in contrast to those living in allopatry, which can be expected in case of adaptive divergence, pairwise morphological distances were calculated in Past. Subsequently, those were compared with uncorrected pairwise genetic distances calculated in MEGA7 [49]. To be able to calculate genetic distances between all morphologically analysed specimens, COI sequences were used as enrichment data were not available for all specimens. In addition, genetic distances between specimens that were also used for target hybrid enrichment were calculated using the EOG sequence alignment. Linear regression between values and significant differences between ranges of genetic distances were again evaluated in Past.

\section{Additional files}

Additional file 1: Phylogenetic EOG tree of the Pallenopsis patagonica species complex. Maximum-Likelihood tree based on concatenated EOG sequences of all samples using P. pilosa and transcriptomic data of Anoplodactylus insignis as outgroup. Bootstrap values are given next to the respective branches. (PDF $296 \mathrm{~kb}$ )

Additional file 2: Phylogenetic SNP tree of the Pallenopsis patagonica species complex. Maximum-Likelihood tree based on aligned SNP data of all Pallenopsis samples. Bootstrap values are given next to the respective branches. (PDF $330 \mathrm{~kb}$ )

Additional file 3: Cross-entropy estimates of genomic sNMF analysis of the Pallenopsis patagonica species complex. Figure showing cross-entropy estimates of genomic sNMF analysis of the Pallenopsis patagonica species complex for 1 to 20 ancestral populations (K value). (PDF 263 kb)

Additional file 4: Morphological measurements of the Pallenopsis patagonica species complex. Table including all measured characters of all individuals used for morphometric analyses. Detailed information about ID, voucher number, sex as well as species and mitochondrial clade assignment is given. Missing values are substituted with a question mark (?). (XLS $158 \mathrm{~kb}$ )

Additional file 5: PCA from morphological data of the Pallenopsis patagonica species complex. PCA plots based on morphological measurements. All mitochondrial clades are indicated by different symbols. Symbols of samples from Patagonian (SUB) have no filling, in contrast to the filled symbols of Antarctica (ANT). Male specimens have a blue, females a red outline. (PDF $569 \mathrm{~kb}$ )

Additional file 6: Matrices of PCA plots based on reduced morphometric data sets of the Pallenopsis patagonica species complex. All combinations of all five axes (PCs) are represented for data sets including A) absolute and B) relative values. Each color represents a different clade (see legend). (PDF $677 \mathrm{~kb}$ )

Additional file 7: Morphological distances against genomic distances. Figure showing morphological distances plotted against genomic distances (based on target hybrid enrichment data) between individuals of the
Pallenopsis patagonica species complex. Red: intraspecific distances (the rightmost red squares represent intraclade distances of SUB_2); grey: interspecific distances. Linear regression line is given $(r=0.51, p<0.0001)$. (PDF $248 \mathrm{~kb}$ )

Additional file 8: Summary of information used for species delimitation of the Pallenopsis patagonica species complex. Table including all information used for species delimitation of the Pallenopsis patagonica species complex. For species delimitation, morphological and genetic analyses were considered. Previously published results are also included. Black filling indicates missing data. (XLS 78 kb) (XLS 78 kb)

Additional file 9: Detailed protocols of methods used. Detailed written protocols for bait enrichment, de novo reference assembly and SNP calling as performed for analyses within the study. (PDF $177 \mathrm{~kb}$ )

\section{Acknowledgements}

We would like to thank Ana Soler Membrives and further anonymous reviewers for putting an enormous effort in reviewing the manuscript and substantially helping improve this study. We are grateful to Sandra Kukowka for advice and assistance in the lab and the Zoological Research Museum Alexander Koenig in Bonn for using its facilities. Simon Vitecek introduced JSD into the beauties of digital drawing and hence speed up the process. Vreni Häussermann and Günter Försterra (Huinay Scientific Field Station, Chile), Chester Sands (British Antarctic Survey, Cambridge, UK), Christoph Held (Alfred-Wegener Institute, Bremerhaven, Germany), Andrew Mahon (Central Michigan University, Michigan, USA) and the Falkland Islands Fisheries Department (Stanley, Falkland Islands) provided samples. This paper is publication \#169 of the Huinay Scientific Field Station.

\section{Funding}

This work was supported by a grant of the Deutsche

Forschungsgemeinschaft (DFG) in the framework of the priority programme "Antarctic Research with comparative investigations in Arctic ice areas" SPP1158 to FL and ME (LE2323/3, ME2683/8). LD was supported by the same organisation with grant DI 2228/1. The "Zempelin-Stiftung im Stifterverband" provided financial support to JD (T0214/32923/2018/sm).

\section{Availability of data and materials}

The datasets generated and analyzed during the current study are included in this published article or available from the corresponding author on reasonable request.

\section{Authors' contributions}

JD, FL and RM designed and directed the project. JD performed lab work, analyzed major parts of the data and led the manuscript writing together with FL and RM. LD and TM analysed sequence data with support from CM and AR. SD and KW assisted with morphological measurements and took morphological images. JD and AR performed the PCA and LDA analyses on morphometric data. JD and RM prepared picture plates. All authors contributed to the final discussion of the data and commented on the manuscript.

Ethics approval and consent to participate Research followed all applicable laws and ethical guidelines per individual countries' requirements. Permits for sampling during Antarctic and Patagonian expeditions were obtained. As no vertebrate animals were impacted by the research no special ethical approvals were needed for this work.

Consent for publication

Not applicable.

\section{Competing interests}

The authors declare that they have no competing interests.

\section{Publisher's Note}

Springer Nature remains neutral with regard to jurisdictional claims in published maps and institutional affiliations. 


\section{Author details}

${ }^{1}$ Aquatic Ecosystem Research, Faculty of Biology, University of Duisburg-Essen, Universitaetsstr. 5, 45141 Essen, Germany. ${ }^{2}$ Zoological Research Museum Alexander Koenig, Statistical Phylogenetics and Phylogenomics, Adenauerallee 160, 53113 Bonn, Germany. ${ }^{3}$ Bavarian State Collection of Zoology - SNSB, Muenchhausenstr. 21, 81247 Munich, Germany. ${ }^{4}$ Faculty of Biology, Technion - Israel Institute of Technology, 3200003 Haifa, Israel. ${ }^{5}$ Centre for Water and Environmental Research (ZWU), University of Duisburg-Essen, Universitaetsstr. 2, 45141 Essen, Germany. ${ }^{6}$ Department Biologie II, LMU Munich, Großhaderner Str. 2, 82152 Planegg-Martinsried, Germany. ${ }^{7}$ GeoBioCenter, LMU Munich, Richard-Wagner-Str. 10, 80333 Munich, Germany.

Received: 27 February 2019 Accepted: 6 May 2019 Published online: 06 September 2019

\section{References}

1. Allcock AL, Strugnell JM. Southern Ocean diversity: new paradigms from molecular ecology. Trends Ecol Evol. 2012;27:520-8. https://doi.org/10.1016/ jtree201205009.

2. Arango CP, Soler-Membrives A, Miller KJ. Genetic differentiation in the circum-Antarctic Sea spider Nymphon australe (Pycnogonida; Nymphonidae). Deep Sea Res Part 2 Top Stud Oceanogr. 2011;58:212-9. https://doi.org/10.1016/j.dsr2.2010.05.019.

3. Arango CP, Wheeler WC. Phylogeny of the sea spiders (Arthropoda, Pycnogonida) based on direct optimisation of six loci and morphology. Cladistics. 2007;23:255-93.

4. Arnaud F, Bamber RN. The Biology of Pycnogonida. In: Blaxter JHS, Southward AJ, editors. Advances in Marine Biology: Academic; 1988. p 1-96. https://doi.org/10.1016/S0065-2881(08)60073-5.

5. Aronesty E. ea-utils: Command-line tools for processing biological sequencing data. 2011. https://github.com/ExpressionAnalysis/ea-utils. Accessed 2 May 2019.

6. Aronson RB, Thatje S, Clarke A, Peck LS, Blake DB, Wilga CD, et al. Climate change and invasibility of the Antarctic benthos. Annu Rev Ecol Evol. 2007; Suppl;38:129-54.

7. Bamber RN, El Nagar A, Arango CP, editors. Pycnobase: World Pycnogonida Database; 2019. http://www.marinespecies.org/pycnobase. Accessed 2 May 2019. https://doi.org/10.14284/360.

8. Bergh R. Report on the Nudibraochiata. Challenger Reports, Zoology. 1884; 10:1-151.

9. Cano-Sánchez E, López-González P. Two new species and new findings in the genus Pallenopsis (Pycnogonida: Pallenopsidae) with an updated identification key to Antarctic and sub-Antarctic species. Zootaxa. 2019;4585: 517-30. https://doi.org/10.11646/zootaxa.4585.3.7.

10. Chapelle G, Peck LS. Polar gigantism dictated by oxygen availability. Nature. 1999;399:114-5.

11. Chernomor $\mathrm{O}$, von Haeseler $\mathrm{A}$, Minh $\mathrm{BQ}$. Terrace aware data structure for phylogenomic inference from supermatrices. Syst Biol. 2016;65:97-1008.

12. Child CA. Pycnogonida of the Southeast Pacific Biological Oceanographic Project (SEPBOB). Smithson Contr Zool I-IV. 1992;1-43.

13. Child CA. Antarctic and Subantarctic Pycnogonida V. The families Pycnogonidae, Phoxichilidiidae, Endeididae, and Callipallenidae, including the genus Pallenopsis. Antarctic Research Series. 1995;69:113-60.

14. Clark WC. Australian Pycnogonida. Rec Aust Mus. 1963;26(1):1-81.

15. Clarke A, Crame JA. The origin of the Southern Ocean marine fauna. Geol Soc Spec Publ. 1989:47:253-68. https://doi.org/10.1144/GSLSP19890470119.

16. Clarke A, Johnston NM. Antarctic marine benthic diversity. Oceanogr Mar Biol Annu Rev. 2003:41:47-114.

17. Convey P, Stevens M, Hodgson D, Smellie J, Hillenbrand C, Barnes D, et al. Exploring biological constraints on the glacial history of Antarctica. Quaternary Sci Rev. 2009;28:3035-48.

18. Coyne J, Orr H. Speciation. Sunderland: Sinauer Associates; 2004. p. 545.

19. Dieckmann U, Doebeli M, Metz JAJ, Tautz D, editors. Adaptive speciation. Cambridge studies in adaptive dynamics. Cambridge: Cambridge University Press; 2004.

20. Dietz L, Arango CP, Halanych KM, Harder AM, Held C, Mahon AR, et al. Regional differentiation and extensive hybridisation between mitochondrial clades of the Southern Ocean giant sea spider Colossendeis megalonyx. Royal Soc Open Sci. 2015a;2:140424.
21. Dietz L, Dömel JS, Leese F, Lehmann T, Melzer RR. Feeding ecology in sea spiders (Arthropoda: Pycnogonida): what do we know? Front Zool. 2018;15: 7. https://doi.org/10.1186/s12983-018-0250-4.

22. Dietz L, Dömel JS, Leese F, Mahon AR, Mayer C. Phylogenomics of the longitarsal Colossendeidae: The evolutionary history of an Antarctic Sea spider radiation. Mol Phylogenet Evol. 2019;136:206-14

23. Dietz L, Krapp F, Hendrickx ME, Arango CP, Krabbe K, Spaak JM, et al. Evidence from morphological and genetic data confirms that Colossendeis tenera Hilton, 1943 (Arthropoda: Pycnogonida), does not belong to the Colossendeis megalonyx Hoek, 1881 complex. Org Divers Evol. 2013;13:151-62. https://doi.org/10.1007/s13127-012-0120-4.

24. Dietz L, Pieper S, Seefeldt MA, Leese F. Morphological and genetic data clarify the taxonomic status of Colossendeis robusta and C. glacialis (Pycnogonida) and reveal overlooked diversity. Arthropod Syst Phyl. 2015b;73:107-28.

25. Dömel JS, Convey P, Leese F. Genetic data support independent glacial refugia and open ocean barriers to dispersal for the Southern Ocean sea spider Austropallene cornigera (Möbius, 1902). J Crust Biol. 2015;35:480-90. https://doi.org/10.1163/1937240X-00002351.

26. Dömel JS, Melzer RR, Harder AM, Mahon AR, Leese F. Nuclear and mitochondrial gene data support recent radiation within the sea spider species complex Pallenopsis patagonica. Front Ecol Evol. 2017;4. https://doi. org/10.3389/fevo201600139.

27. Faircloth BC, McCormack JE, Crawford NG, Harvey MG, Brumfield RT, Glenn TC. Ultraconserved elements anchor thousands of genetic markers spanning multiple evolutionary timescales. Syst Biol. 2012;61:717-26.

28. Fernández R, Edgecombe GD, Giribet G. Exploring phylogenetic relationships within Myriapoda and the effects of matrix composition and occupancy on Phylogenomic reconstruction. Syst Biol. 2016;65(5):871-89. https://doi.org/10.1093/sysbio/syw041.

29. Försterra G. Ecological and Biogeographical aspects of the Chilean fjord region. In: Häussermann V, Försterra G, editors. Marine Benthic Fauna of Chilean Patagonia: illustrated identification guide Puerto Montt. Chile: Nature in Focus; 2009. p. 61-76.

30. Fraser Cl, Nikula R, Ruzzante DE, Waters JM. Poleward bound: biological impacts of southern hemisphere glaciation. Trends Ecol Evol. 2012;27:462-71

31. Frichot E, François O. LEA: an R package for landscape and ecological association studies. Methods Ecol Evol. 2015;6:925-9. https://doi.org/10. 1111/2041-210X12382

32. Gordon I. Pycnogonida. B.A.N.Z. Antarctic Research Expedition 1929 - 1931. Reports - series B (zoology and botany). 1944;5(1):1-72.

33. Griffiths $\mathrm{H}$. Antarctic marine biodiversity - what do we know about the distribution of life in the Southern Ocean? PLOS One. 2010;5:e11683.

34. Halanych KM, Mahon AR. Challenging dogma concerning biogeographic patterns of Antarctica and the Southern Ocean. Annu Rev Ecol Evol S. 2018; 49:355-78.

35. Hammer $\varnothing$, Harper DAT. Paleontological Data Analysis. Oxford: Blackwell Publishing; 2006.

36. Hammer $\varnothing$, Harper DAT, Ryan PD. PAST: paleontological statistics software package for education and data analysis. Palaeontol Electron. 2001;4:1-9.

37. Harder AM, Halanych KM, Mahon AR. Diversity and distribution within the sea spider genus Pallenopsis (Chelicerata: Pycnogonida) in the Western Antarctic as revealed by mitochondrial DNA. Polar Biol. 2016;39:677-88. https://doi.org/10.1007/s00300-015-1823-8.

38. Held C, Leese F. The utility of fast evolving molecular markers for studying speciation in the Antarctic benthos. Polar Biol. 2007;30:513-21.

39. Held C, Wägele J-W. Cryptic speciation in the giant Antarctic isopod Glyptonotus antarcticus (Isopoda: Valvifera: Chaetiliidae). Sci Mar. 2005;69(2):175-81.

40. Hodgson TV. Pycnogonida. National Antarctic Expedition 1901-1904 Reports of the National Antarctic Expedition of 1901-1904. Nat Hist. 1907:3:1-72.

41. Hodgson TV. The Pycnogonida collected by the Gauss in the Antarctic regions, 1901-03; preliminary report. Ann Mag Nat Hist. 1915;15(8):141-9.

42. Hoek PPC. Report on the Pycnogonida dredged by HMS Challenger 187376 reports of the scientific results of the exploring voyage of HMS Challenger, vol. 3; 1881. p. 1-167.

43. Irisarri I, Singh P, Koblmüller S, Torres-Dowdall J, Henning F, Franchini P, et al. Phylogenomics uncovers early hybridization and adaptive loci shaping the radiation of Lake Tanganyika cichlid fishes. Nat Commun. 2018;9:3159. 
44. Jones MB. The mouthparts of the members of the Jaera albifrons group of species (Crustacea: Isopoda). Mar Biol. 1972;14:264. https://doi.org/10.1007/ BF00348290.

45. Kalyaanamoorthy S, Minh BQ, Wong TKF, von Haeseler A, Jermiin LS. ModelFinder: fast model selection for accurate phylogenetic estimates. Nat Methods. 2017;14:587-9.

46. Katoh K, Standley DM. MAFFT multiple sequence alignment software version 7: improvements in performance and usability. Mol Biol Evol. 2013;30:772-80.

47. Kosakovsky Pond SL, Frost SDW, Muse SV. HyPhy: hypothesis testing using phylogenies. Bioinformatics. 2005;21(5):676-9.

48. Krabbe K, Leese F, Mayer C, Tollrian R, Held C. Cryptic mitochondrial lineages in the widespread pycnogonid Colossendeis megalonyx Hoek, 1881 from Antarctic and Subantarctic waters. Polar Biol. 2010;33:281-92.

49. Kumar S, Stecher G, Tamura K. MEGA7: Molecular evolutionary genetics analysis version 7.0. Mol Biol Evol. 2016:33(1):1870-4.

50. Lee T-H, Guo H, Wang X, Kim C, Paterson AH. SNPhylo: a pipeline to construct a phylogenetic tree from huge SNP data. BMC Genomics. 2014;15: 162. https://doi.org/10.1186/1471-2164-15-162

51. Leese F, Kop A, Wägele J-W, Held C. Cryptic speciation in a benthic isopod from Patagonian and Falkland Island waters and the impact of glaciations on its population structure. Front Zool. 2008:5:19.

52. Lehmann T, Heß M, Melzer RR. Sense organs in Pycnogonida: A review. Acta Zool. 2017. https://doi.org/10.1111/azo12207.

53. Li H, Handsaker B, Wysoker A, Fennell T, Ruan J, Homer N, Marth G, Abecasis G, Durbin R. The Sequence Alignment/Map format and SAMtools. Bioinformatics. 2009;25:2078-9. https://doi.org/10.1093/bioinformatics/btp352.

54. Linse K, Cope T, Lörz AN, Sands C. Is the Scotia Sea a Centre of Antarctic marine diversification? Some evidence of cryptic speciation in the circumAntarctic bivalve Lissarca notorcadensis (Arcoidea: Philobryidae). Polar Biol. 2007;30:1059. https://doi.org/10.1007/s00300-007-0265-3.

55. Loman JCC. The Pycnogonida. Further zoological results of the Swedish Antarctic expedition. 1; 1923. p. 1-41.

56. Lovett DL, Felder DL. Application of regression techniques to studies of relative growth in crustaceans. J Crust Biol. 1989;9(4):529-39.

57. Mahon A, Arango C, Halanych K. Genetic diversity of Nymphon (Arthropoda: Pycnogonida: Nymphonidae) along the Antarctic peninsula with a focus on Nymphon australe Hodgson, 1902. Mar Biol. 2008;155:315-23.

58. Marden CJ, Clapperton CM. Fluctuations of the south Patagonian ice-field during the last glaciation and the Holocene. J Quaternary Sci. 1995;10:197209. https://doi.org/10.1002/jqs3390100302.

59. Mayer C, Sann M, Donath A, Meixner M, Podsiadlowski L, Peters RS, et al. BaitFisher: a software package for multispecies target DNA enrichment probe design. Mol Biol Evol. 2016;33:1875-86.

60. Mello-Leitão ACG. Uma nova espécie de Pallenopsis do Atlântico Sul (Pantopoda, Pallenidae). Arquivos do Museu Paranaense. 1949;8: 299-307.

61. Möbius K. Die Pantopoden der Deutschen Tiefsee- Expedition, 1898-99. Wissenschaftliche Ergebnisse der Deutschen Tiefsee-Expedition auf dem Dampfer Valdivia', 1898-1899, vol. 3; 1902. p. 177-96.

62. Munilla T, Soler-Membrives A. Check-list of the pycnogonids from Antarctic and sub-Antarctic waters: zoogeographic implications. Antarct Sci. 2009;21:99-111.

63. Murrell B, Moola S, Mabona A, Weighill T, Sheward D, Kosakovsky Pond $S L$, et al. FUBAR: a fast, unconstrained Bayesian AppRoximation for inferring selection. Mol Biol Evol. 2013;30(5):1196-205. https://doi.org/10. 1093/molbev/mst030

64. Murrell B, Weaver S, Smith MD, Wertheim JO, Murrell S, Aylward A, et al. Genewide identification of episodic selection. Mol Biol Evol. 2015;32:1365-71.

65. Murrell B, Wertheim JO, Moola S, Weighill T, Scheffler K, Kosakovsky Pond SL. Detecting individual sites subject to episodic diversifying selection. PLoS Genet. 2012;8(7):e1002764. https://doi.org/10.1371/ journalpgen 1002764 .

66. Nguyen LT, Schmidt HA, von Haeseler A, Minh BQ. IQ-TREE: a fast and effective stochastic algorithm for estimating maximum-likelihood phylogenies. Mol Biol Evol. 2015;32:268-74.

67. Petersen $M$, Meusemann $K$, Donath A, Dowling D, Liu S, Peters RS, et al. Orthograph: a versatile tool for mapping coding nucleotide sequences to clusters of orthologous genes. BMC Bioinformatics. 2017;18:111.

68. Pushkin AF. Revision of the pycnogonids (Pantopoda) of the Pallenopsis patagonica group from Antarctica and adjacent waters. Byulleten Sovietskoi Antarkticheskoi Ekspeditsii. 1975;90:72-83.
69. Pushkin AF. The pycnogonids fauna of the South Ocean: biological results of the soviet Antarctic expeditions. Russian Academy of Sciences: Exploration of the Fauna of the Seas St Petersburg/Portorosa; 1993. p. 1-397.

70. Rutschmann S, Matschiner M, Damerau M, Muschick M, Lehmann M, Hanel $\mathrm{R}$, et al. Parallel ecological diversification in Antarctic notothenioid fishes as evidence for adaptive radiation. Mol Ecol. 2011;20:4707-21.

71. Sabroux R, Corbari L, Krapp F, Bonillo C, le Prieur S, Hassanin A. Biodiversity and phylogeny of Ammotheidae (Arthropoda: Pycnogonida). Eur J Taxonomy. 2017;286:1-33.

72. Schluter D. Ecological character displacement in adaptive radiation. Am Nat 2000;156:Suppl 4-16.

73. Smith MD, Wertheim JO, Weaver S, Murrell B, Scheffler K, Kosakovsky Pond SK. Less is more: an adaptive branch-site random effects model for efficient detection of episodic diversifying selection. Mol Biol Evol. 2015;32:1342-53.

74. Soler-Membrives A, Linse K, Miller KJ, Arango CP. Genetic signature of last glacial maximum regional refugia in a circum-Antarctic Sea spider. Royal Soc Open Sci. 2017:4. https://doi.org/10.1098/rsos.170615.

75. Stock JH. Pantopoden aus dem Zoologischen Museum Hamburg. Mitteilungen aus dem Hamburgischen Zoologischen Museum und Institut, vol. 55; 1957. p. 81-106.

77. Sudhaus W, Kiontke K. Comparison of the cryptic nematode species Caenorhabditis brenneri sp. n. and C. remanei (Nematoda: Rhabditidae) with the stem species pattern of the Caenorhabditis Elegans group. Zootaxa. 2007;1456:45-62.

78. Thatje $\mathrm{S}$, Hillenbrand CD, Larter R. On the origin of Antarctic marine benthic community structure. Trends Ecol Evol. 2005;20:534-40. https://doi.org/10. 1016/jtree200507010.

79. Thornhill DJ, Mahon AR, Norenburg JL, Halanych KM. Open-ocean barriers to dispersal: a test case with the Antarctic polar front and the ribbon worm Parborlasia corrugatus (Nemertea: Lineidae). Mol Ecol. 2008:17:5104-17.

80. Wagner P, Dömel JS, Hofmann M, Hübner J, Leese F, Melzer RR. Comparative study of bisected proboscides of Pycnogonida. Org Divers Evol. 2017;17:121. https://doi.org/10.1007/s13127-016-0310-6.

81. Weis A, Meyer R, Dietz L, Dömel JS, Leese F, Melzer RR. Pallenopsis patagonica (Hoek, 1881) - a species complex revealed by morphology and DNA barcoding, with description of a new species of Pallenopsis Wilson, 1881. Zool J Linnean Soc. 2014;170:110-31. https://doi.org/10.1111/zoj12097.

82. Wilson EB. Reports on the Pycnogonida. Reports on the results of dredging, under the supervision of Alexander Agassiz, along the East Coast of the United States, during the summer of 1880 , by the U.S. coast survey steamer "Blake", Commander J R Bartlett, USN Commanding. Bull Mus Comp Zool. 1881;8:239-56.

83. Wilson NG, Schrödl M, Halanych KM. Ocean barriers and glaciation: evidence for explosive radiation of mitochondrial lineages in the Antarctic Sea slug Doris kerguelenensis (Mollusca, Nudibranchia). Mol Ecol. 2009;18: 965-84. https://doi.org/10.1111/j1365-294X200804071x

84. Zdobnov EM, Tegenfeldt F, Kuznetsov D, Waterhouse RM, Simao FA, loannidis P, Seppey M, Loetscher A, Kriventseve EV. OrthoDB v9.1: cataloging evolutionary and functional annotations for animal, fungal, plant, archaeal, bacterial and viral orthologs. Nucleic Acids Res. 2017;4:D744-9.

85. Zheng X, Levine D, Shen J, Gogarten SM, Laurie C, Weir BS. A highperformance computing toolset for relatedness and principal component analysis of SNP data. Bioinformatics. 2012. https://doi.org/10.1093/ bioinformatics/bts606.

\section{Ready to submit your research? Choose BMC and benefit from}

- fast, convenient online submission

- thorough peer review by experienced researchers in your field

- rapid publication on acceptance

- support for research data, including large and complex data types

- gold Open Access which fosters wider collaboration and increased citations

- maximum visibility for your research: over $100 \mathrm{M}$ website views per year

At BMC, research is always in progress.

Learn more biomedcentral.com/submission 